\title{
Seasonal and Regional Variation of Pan-Arctic Surface Air Temperature Over the Instrumental Record
}

\author{
James E. Overland ${ }^{1}$ \\ Michael C. Spillane ${ }^{2}$ \\ Donald B. Percival ${ }^{3}$ \\ Harold O. Mofjeld ${ }^{1}$ \\ ${ }^{1}$ NOAA/Pacific Marine Environmental Laboratory \\ 7600 Sand Point Way NE \\ Seattle, WA 98115-6349 \\ ${ }^{2}$ Joint Institute for the Study of the Atmosphere and Oceans \\ Box 354235, University of Washington \\ Seattle, WA 98195-4235 \\ ${ }^{3}$ Applied Physics Laboratory \\ Box 355640 \\ University of Washington \\ Seattle, WA 98195-5640
}

For submission to Journal of Climate

23 July 2003

Contribution 2546 from NOAA/Pacific Marine Environmental Laboratory 


\section{Abstract}

Historical surface air temperature (SAT) records from 59 Arctic stations north of $64^{\circ} \mathrm{N}$ show monthly anomalies of several degrees and large spatial teleconnectivity yet major seasonal and regional differences, based on time/longitude plots of SAT anomalies and Principal Component Analysis (PCA). Using monthly station data rather than gridded fields for this analysis highlights the importance of considering record length in calculating reliable Arctic change estimates; for example, we contrast PCA performed on 11 stations beginning in 1886, 20 stations beginning in 1912, and 45 stations beginning in 1936. While often there is a well-known interdecadal negative covariability in winter between Scandinavia and Baffin Bay in the historical SATs, long-term changes in the remainder of the Arctic are most evident in spring, with cool temperatures before 1920 and Arctic-wide warming in the 1990s. Summer anomalies are generally weaker than spring or winter but tend to mirror spring conditions before 1920 and in recent decades. Temperature advection in the trough-ridge structure in the positive phase of the Arctic Oscillation (AO) in the N. Atlantic establishes wintertime temperature anomalies in adjacent regions, while the zonal/annular nature of the $\mathrm{AO}$ in the remainder of the Arctic must break down in spring to promote meridional temperature advection. There are regional/decadal warm events during winter and spring in the 1930 s to 1950 s, but meteorological analysis suggests that these SAT anomalies are the result of intrinsic variability in region flow patterns. The mid-century events contrast with an Arctic-wide AO influence in the 1990s. We also present a conceptual model for decadal variability of the Arctic system consisting of chaotic behavior of the polar vortex. Regional feedbacks in the Arctic can act as partial multi-year memory for the vortex through amplification of ocean/sea-ice/land-vegetation changes, while the vortex in turn is often driven by north/south differences in radiational forcing from $\mathrm{CO}_{2}$, aerosols, solar absorption and volcanic influence. The preponderance of evidence supports the conclusion that warm SAT anomalies in spring for the decade for the 1990s had the greatest longitudinal extent in the instrumental record. 


\section{Introduction}

In this paper we further the analysis of Arctic variability by reexamination of the surface air temperature (SAT) from major weather observation stations with long record lengths. We focus on changes in each season and in different regions of the Arctic, rather than concentrating on annual zonal averages, because extensive averaging can often obscure the underlying physics. With recent understanding of the North Atlantic Oscillation (NAO) and Arctic Oscillation (AO) dynamics and their relation to stratospheric cooling in winter and spring, we can also develop a more regionally and seasonally dependent conceptual model of Arctic temperature change. Our analysis also provides a reevaluation of the instrumental temperature record in that we base our methodology on station data rather than gridded analyses as in earlier studies. This approach avoids the possible introduction of artifacts due to gridding, which is particularly important in understanding the results from Principal Component Analysis (PCA).

The most difficult issue in retrospective analyses of the Arctic is the range of starting dates in the instrumental record. Although data coverage is far from complete, there is considerable information from the land areas of the Arctic dating from the early 20th century. Przybylak (2000) notes that there is good Arctic coverage since the 1950s. Due to the strong spatial correlation within Arctic subregions (Przybylak 2003) however, there is adequate coverage on decadal scales since the 1930s. Unfortunately, stations beginning in the mid-1930s

do not fully resolve the mid-century warming episodes, and records from the 1880 s are limited to only two subregions, W. Greenland and Scandinavia, which show a close negative relation in temperature. Representative hemispheric spatial coverage (20 stations) is available beginning in 1912 when Svalbard came on line, and we focus primarily on this period.

The fourth International Polar Year is scheduled for 2007 and is focused on unresolved issues of polar influence on climate variability. It is fitting to review the data that began with the first polar year (1882-1883), which marked a transition from exploration to scientific study in the Arctic. It is also fitting to update the analyses of the many authors in the 1920s-1940s who noted 
the warm temperature anomalies of the period (Ahlmann 1948) and pioneered the concept of high-latitude climate variability, in contrast to the prevailing uniformitarianism.

Recent studies show considerable change in the Arctic over the previous three decades in both physical and biological indicators (Serreze et al. 2000; Overland et al. 2003). These indicators suggest a shift in atmospheric patterns such as the $\mathrm{AO}$ and related stratospheric cooling around 1989, while sub-Arctic records such as permafrost temperatures show linear trends from the 1970s. It is important to put Arctic change in the past 30 years in the context of the period from the early 1800 s to present, noting the warm temperature anomalies in the mid 20th century as the end of a long period of rising temperatures. Recent analyses of the midcentury warming suggest that internal atmospheric variability is important to its explanation and that the regional dynamics were different compared to recent decades (Hanssen-Bauer and Førland 1998; Bengtsson et al. 2003; Johannessen et al. 2003). As we shall show, it is also important to note the large seasonal and regional differences in understanding temperature change on decadal time scales throughout the 20th century.

Two recent studies call into question whether changes in the recent period (1990s) are unique compared to longitudinally averaged, historical temperature data; both papers note the warm events in 1920-1950. Przybylak (2002) states that while 1991-2000 is the warmest decade of the second half of the 20th century, "the question remains whether the tendency will continue and whether the first decades of the 21 st century will exceed the levels of the 1930s and 1940s." Polyakov et al. (2002) concludes that Arctic air-temperature trends during the 20th century do not support the predicted polar amplification of global warming, and propose a 50-year Low Frequency Oscillation (LFO) in Arctic temperatures.

In contrast, modeling studies for the IPCC report (Stott et al. 2001) and proxy temperature records (Crowley 2000; Biffra and Osborn 2002) make the case for recent warming relative to the previous two centuries based on external forcing driven by solar variations, aerosols from volcanoes, and carbon dioxide. In particular, the cool period in the first half of the 1800 s can in part be associated with major aerosol production, while the warm period in the first half of the 
20th century had almost no volcanic production (Robock 2000). Warming in the last half of the 20th century is presented as an argument for the uniqueness of recent $\mathrm{CO}_{2}$ increases in overcoming the increase in volcanic influence in the last 50 years. Thus we have competing visions for the future at high northern latitudes: a 50-year cycle going to colder temperatures or continued warming.

In resolving this issue it is important to resolve methodological issues. The usual formulation of PCA requires a complete temporal/spatial data matrix. Previous analyses beginning in 1881 and 1892 (Kelly et al. 1982; Semenov and Bengtsson 2003) rely on gridded fields where much of the area in early years is completed by a fill-in rule. We avoid the need for gridding by conducting three PCAs with time series limited to those stations beginning in or before 1886, 1912, and 1936. This approach requires that we fill only a few temporal data gaps. We contrast the use of a Monte Carlo approach with a statistical procedure for calculating principal components from mildly gappy data (Davis 1976). We also limit our PCA to north of $64^{\circ} \mathrm{N}$, remaining Arctic centric, while earlier studies included considerably more stations southward to $60^{\circ} \mathrm{N}$ and $40^{\circ} \mathrm{N}$.

The next section discusses the available data series. This is followed by a visual and semiquantitative (PCA) inspection and interpretation of the series over the nearly complete historical record of SAT.

\section{Data sources, preparation, and analysis methods for monthly SAT data}

\section{a. Sources of station records}

The long-term records of monthly mean SAT are based primarily on the Global Historical Climatology Network (GHCN) dataset version-2 (http:/www.ncdc.noaa.gov/cgi-bin/ res40.pl?page $=$ ghen.html). The data are organized by World Meteorological Organization (WMO) location index, with records from adjacent locations supplementing that from the primary site. A secondary source of monthly mean data is the World Monthly Surface 
Climatology (WMSC) dataset (http://dss.ucar.edu/catalogs/ranges/range560.html). The selected time series were cross checked with the data set from Polyakov et al. (2002).

\section{b. Time series selection}

It is important to define a southern border of the Arctic for climatological study. There are few stations north of $80^{\circ} \mathrm{N}$, but a major increase in the number of stations as one extends the southern domain south from $65^{\circ} \mathrm{N}$ to $60^{\circ} \mathrm{N}$. Many authors use a fixed latitude such as $60^{\circ} \mathrm{N}$ (Walsh 1977) or $62^{\circ} \mathrm{N}$ (Polyakov et al. 2002). Climatological/botanical limits include the tundra line $\left(<10^{\circ}\right.$ maximum monthly temperature) or a more comprehensive multiseasonal, multimeteorological element approach (Przbylak 2000). The definition is more complex if one considers the southern limits of hydrologic river basins, which flow into the Arctic. There is no firm selection criteria.

For our purpose, we propose a southern limit of $64^{\circ} \mathrm{N}$. Adding the many stations south of this latitude would bias results to the sub-Arctic region. On the other hand, $64^{\circ} \mathrm{N}$ provides a reasonable climatological limit for stations that lie north of the Arctic front in winter and provide sufficient geographic and temporal station coverage. For example, we include Fairbanks, AK but not Anchorage. We also include some interior stations in northern Canada and Russia that have long instrumental records. In maps of recent temperature trends (Chapman and Walsh 1993) there are north-south orientations to anomalies, which suggest these relatively lower latitude stations can be representative of higher latitudes. Another concern is the Scandinavian peninsula, which is subject to strong warm air advection. Przbylak (2000) excludes this region while Polyakov et al. (2002) includes stations south to Thorshaven and Aberdeen. Our criteria includes northern Scandinavian stations which are often subject to Arctic air masses; we will show later that these stations correlate well with anomalies at Arctic stations further east. They are also important as they often form a dipole (NAO) with stations in the Baffin Bay region.

Therefore to minimize data gaps and maximize the number of useable long time series, data were combined as follows: 
- all stations north of $64^{\circ} \mathrm{N}$ in the GHCN database were selected; this avoided biasing an "Arctic" subset with the large number of stations from $60-64^{\circ} \mathrm{N}$,

- each record was initially populated with data from the primary WMO location,

- data gaps were successively filled using information from the supplementary adjacent location, if available, in the order they appear in the GHCN Version-2 file,

- updates, and some insertions in earlier gaps, were made based on the WMSC (ds570.0) dataset,

- time series, for each station and month, were quality-checked and a few spurious values were eliminated, and

- stations starting after 1936 were not used, with a few exceptions where regional coverage is sparse, such as the Canadian Arctic.

The zonal coverage of the identified stations is not uniform. In data rich areas, such as Scandinavia and the western Russian Federation, some series were removed; the stations retained were those deemed optimal in terms of duration of coverage, continuity of data, and representativeness. The result is a set of 59 stations which will be used for visual inspection. They are plotted in Fig. 1 and listed in Table 1 by longitude. An overall measure of completeness for each station is given by the percent of monthly observations present in the available period for that location.

Uniform station density and continuity are particularly important for the PCA where each station provides a weight function. For this reason we removed additional stations in northern Scandinavia and Iceland before calculating the PCA.

\section{c. Methods}

For visual presentation of time series and principal components, we apply a 5-year running average. We justify the five-year smoothing as an approach for investigating centurylong decadal change. Climate records often indicate change through a shift in the frequency of extreme events. For example, the number of winters with cold stratospheric temperature 
anomalies increased in the 1990s relative to the 1980s. Changes in the frequency of volcanic events can affect regional and hemispheric SAT on decadal time scales. There are natural changes in storminess from year-to-year. There is also the potential for a high-latitude influence from the quasi-biennial-oscillation. Thus decadal scales appear to be appropriate to address climate variability over the instrumental record; for visual inspection it is helpful to suppress the interannual scale.

We conduct a PCA for comparison with visual inspection of the time series. Two important issues are gap filling of the data and the variable length of the records. With regard to the few remaining data gaps, we use both a Monte Carlo approach, where missing data are filled by sampling from a statistical model and repeating the PCA multiple times, and an estimation procedure for the PCs (Davis 1976). Both approaches gave similar results and indicate that the PCAs are not materially influenced by the missing temporal data. We report the results from the estimation procedure. The decreasing number of stations in the early record is more problematical. Kelley et al. (1982) performs PCA for 1881-1980 by replacing missing observations, as represented by selected $10^{\circ} \times 5^{\circ}$ longitude/latitude cells, by the long term average for the particular grid point. Semenov and Bengtsson (2003) also used gridded data beginning in 1892 . To keep as close to the observed data as possible, we perform three separate PCAs on subsets of the 59 stations based on length or record: 11 stations beginning in 1886 which are from Greenland and Scandinavia, 20 stations beginning in 1912, and 45 stations beginning in 1936. These data are available at www.unaami.gov.

\section{Visual inspection and PCA of historical temperature time series}

As discussed below, visual inspection suggests strong spatial correlation of temperature anomalies within different segments of the Arctic at decadal scales. We will refer to six sectors in the text corresponding to Scandinavia, Siberia, Beringia, NW Canada, Baffin Bay, and E. Greenland; these regions are located in Fig. 1. The Scandinavian sector extends eastward to Archangelsk and includes the islands of the northeastern Atlantic. Beringia represents the region 
on both sides of Bering Strait. The inland location of Fairbanks groups more strongly with NW Canada than with Beringia. The Baffin Bay region consists of land stations from both western Greenland and northeastern Canada. The E. Greenland sector includes Iceland. These locations are approximately the same climatic regions proposed by Przybylak (2003), except for his combining E. Greenland with Scandinavia, which from visual inspection of the station time series is not unreasonable. The longest records are from Scandinavia, Baffin Bay, and eastern Greenland, but there are several representative sites in other regions which begin before 1900 .

\section{a. Winter}

We begin the analysis by inspecting the time/longitude plots of temperature anomalies relative to 1961-1990 means for December-January (Fig. 2). Time/longitude plots for individual months are available at www.unaami.noaa.gov. The Scandinavian sector (Stns. 1-9) shows evidence of an interdecadal signal with alternating cold and warm anomaly periods throughout the record back to the 1860 s; there are two periods with long warm anomalies: 1890-1910 and 1920-1938. The E. Greenland sector (Stns. 54-59) often follows the Scandinavian sector; the exceptions are the lack of a cooling period around 1940 and of a warm period in the 1970s.

In Siberia (Stns. 10-26) generally cold temperature anomalies occurred before 1920 based on Stns. 16, 19, and 25, followed by a warm period in the 1920s through the 1950s. Maximum warm anomalies in the late 1930s and early 1940s occur several years later than the mid 1930s maximum in Scandinavia. After the 1970s the tendency for Siberia is to be out of phase with Scandinavia with a warm period in the 1980s and a cool period in the late 1990s, not unlike 1890-1910. Far Eastern Siberia and North America generally stayed cool until the mid 1970s, with Beringia (Stns. 27-36) turning cold again starting in the late 1980s and NW Canada (Stns. 37-44) remaining warm.

The Baffin Bay region (Stns. 45-53) was especially cold during 1865-1910 when Europe was warm. It was in phase with Europe from the late 1910s to 1948, with a cold followed by a 
warm period, but again shows an out-of-phase relation for three cold and two warm events from 1950 to 1995. For the late 1990s Baffin Bay and Scandinavia are both warm.

Figure 3 (top) shows the stations used for the three PCAs. Different symbols denote those stations beginning in 1886 (11 stations), 1912 (20 stations), and 1936 (45 stations). Note that the later analyses include the stations from the earlier period. The first pattern (A) for winter December/January is represented by the first EOF modes, plotted on a longitudinal axis for the three separate periods and accounting for at least $30 \%$ of the interannual variance. All three EOFs (station weights) show similar station contributions, although the EOF for the series beginning in 1912 shows an enhanced contribution from the Beringia region. In agreement with Fig. 2, pattern (A) suggests the well-known out-of-phase behavior in winter (NAO or seesaw) between Baffin Bay and Scandinavia (van Loon and Rogers 1978). The first principal component time series in winter for the three record lengths (Fig. 3, bottom) show a strong interdecadal signal.

Several authors show that the increase in European winter temperatures in the 1920s were associated with increased westerlies across the North Atlantic producing warm air advection into Europe; at the same time Baffin Bay was cold, suggesting an NAO connection (Rogers 1985, Fu et al. 1999). Fu et al. (1999) notes considerable strengthening and northward movement of the North Atlantic high pressure region during this period, suggesting the influence of NAO midlatitude processes. Our PCA and Fig. 2 indicate that the Baffin Bay region in the recent half century was out of phase with Scandinavia, showing a continuing interdecadal pattern as earlier in the century. Temperatures over the sea ice in the central Arctic during the 1980s and 1990s also have this wintertime seesaw pattern (Rigor et al. 2000); there was a warming in the European sector of the Arctic, but a cooling trend in the remainder of the Arctic. During the positive phase of the AO in the 1990s tropospheric/stratospheric coupling is considered important in maintaining this pattern (Newman et al. 2001; Moritz et al. 2002; Ambaum and Hoskins 2002).

For comparison with the winter pattern (A), there are instrumental records which extend back to the 1700s just south of our region in northern Europe, e.g., Stockholm (Moberg et al. 
2002). Figure 4 shows a multi-resolution analysis (MRA) based upon the maximal overlap discrete wavelet transform and the Haar wavelet (Percival and Mofjeld 1997). This MRA is an additive decomposition of the January temperature record for Stockholm in terms of a 64-year interval (S5) and bands of 2-4, 4-8, 8-16, 16-32, and 32-64 years (D 1 to D5). The $>64$ year curve shows a long term trend over the previous two centuries. The changes in 16-32 year band (D4) show a strong interdecadal signal in the 20th century that reflects a NAO signature, indicating the predominance of N. Atlantic versus polar Arctic air masses. In the 19th century, however, temperatures were colder and the impact of the NAO appears diminished. This shift is also suggested by a "regime change" in Baltic Sea ice coverage in the late 1800s (Omstedt and Chen 2001).

The second wintertime pattern (B) (Fig. 5) is represented by EOF mode 2 for the analysis beginning in 1912 and EOF mode 3 for that beginning in 1936 (Table 2). These EOFs show an in-phase behavior from Siberia eastward through NW Canada. The nearly pan-Arctic in-phase behavior, excluding Baffin Bay and Scandinavia, point to a simultaneous cold event in the PC series (Fig. 5, bottom) in the late 1910s and a warm Beringia and Siberia event in the 1980s. Although a regression fit to the $1912 \mathrm{PC}$ record leads to a positive slope, the analysis of Rogers and Mosley-Thompson (1995) suggests that the mild Siberian winters of the 1980s, also indicated in Fig. 2, were associated with increased storminess northwest of Siberia while NAO appears to have had little influence. Figure 6 shows the SAT anomalies and the sea level pressure (SLP) anomalies for December/January 1983-1985, when there is extensive warming in Beringia and Siberia and cooling in Baffin Bay. The complicated structure of the SLP field does not suggest a coherent large-scale climate pattern, yet the strong temperature anomalies of the 1980s are selected by the PCA as an important event.

The third wintertime pattern (C) is based on EOF mode 3 for the 1912 records and shows an in-phase behavior for Baffin Bay and Scandinavia (Fig. 7). Pattern (C) is also supported by the second EOF for the records beginning in 1886, which has stations in only these two regions. The PCs (Fig. 7, bottom) show a general increase in positive values beginning from 1923 through 
1945, which is again evident in Fig. 2. In contrast to the 1920s, the 1930s (pattern C) has Scandinavia and Baffin Bay in phase. Hanssen-Bauer and Førland (1998) note that the continued warming at Svalbard (Stn. 2) in the 1930s was not associated with NAO type warm air advection processes as in the 1990s. Bengtsson et al. (2003) relate the warming in the 1930s to a high Arctic mode of internal variability, separate from the more subarctic NAO influence. Skeie (2000) and Bengtsson et al. (2003) make the case that sea ice variability in the Barents/Kara Sea provides a positive feedback to maintain the warm temperature anomalies. However, the Baffin Bay area also contributes to pattern $\mathrm{C}$, so changes in atmospheric circulation on larger scales are also indicated. Finally, EOF mode 2 in winter for the short record (not shown) had an Arcticwide in phase behavior not present in the longer analyses.

In summary, based on both visual inspection and PCA of the winter (December-January series), the Scandinavian sector shows a strong interdecadal signature throughout the instrumental record with extended warm temperatures in the mid 1930s. Siberia had warm anomalies from the 1930s through the late 1940s, generally in phase but occurring somewhat later than Scandinavia. A major event was the warm anomalies across Siberia and North America (Stns. 7-46) in the 1980s when Scandinavia was cool; subsequently this event has reversed for all regions except NE Canada. Our decadal analysis reinforces the point made by other authors that care must be taken in selecting intervals for calculating linear trends. For example, from examining Fig. 2, Siberia and Alaska (Stns. 24-37) would show a positive trend over the previous 40 years in a regression analysis even though the main feature was a single decadal warming episode in the 1980s that was followed by cool anomalies.

\section{b. Spring}

Spring as represented by April surface temperature anomalies (Fig. 8) is the time when sunlight returns to the Arctic and the winter stratospheric polar vortex weakens and breaks down. The most striking feature in the figure is the longitudinal bandedness of the anomalies; this bandedness cannot be attributed to longitudinal smoothing since we have applied none. The 
bandedness is shown in the large warm anomalies since the late 1980s, with particularly strong anomalies in Siberia, Beringia, and NW Canada (Stns. 11-50). Except for a short period in the mid 1970s, the Arctic was cool in spring from the 1960s to the late 1980s. There are previous isolated warm anomalies in the late 1940s/early 1950s, covering Siberia, Beringia, NW Canada, and Baffin Bay; these regions match the magnitude of the warmest anomalies in the 1990s.

The Scandinavian sector (Stns. 1-9) does not contain strong anomalies during spring of either sign over the length of the record. However, we do note cool anomalies in spring in the 1920/1930s in contrast to the warm wintertime anomalies. On the other hand, Baffin Bay (Stns. 45-53) was warm in both winter and spring during the 1930s. The first PCA pattern (A) for April (Fig. 9) is represented by the EOF mode 1 for all three records beginning in 1886, 1912, and 1936. It shows an in phase behavior for the Arctic, but with little contribution from the Scandinavia, E. Greenland, or Baffin Bay sectors. The PC time series for these three estimates (Fig. 9, bottom panel) show high values in the 1940s and early 1950s and also over much of the 1990s, which is consistent with Fig. 8. The recent warming is of particular interest. Rigor et al. (2000) found that during spring almost all the central Arctic shows significant warming trends over the previous 20 years. The warming in Alaska relates to changes in the frequency of southerly warm air advection events during the breakdown of the polar vortex (Overland et al. 2002). The importance of this spring pattern (A) in contrast to the winter pattern (A) is highlighted by Rogers and McHugh (2002), who note the similarity of the AO and NAO pattern in winter, but a separation of an Arctic-centric AO pattern from a more N. Atlantic-oriented NAO pattern during spring.

The second pattern (B) for spring (Fig. 10), supported by all three EOF mode 2s, suggests a plus-minus shape with North America out-of-phase with Eurasia. The PC time series of these EOFs (Fig. 10, bottom) point to an event from the mid 1920s through 1940 that can be seen in Fig. 8.

While there has been considerable discussion in the literature about the mid-century warming in winter during the 1930s, little attention has been given to the warm periods in spring 
during the early 1940s and 1950s. To compare the meteorological conditions in recent springs to these earlier periods, Fig. 11 (right) shows composite plots of the SAT anomalies for April and SLP for March-April for the four warm years 1990, 1993, 1995, and 1997. Note that the wind patterns (based on SLP) in both March and April will impact April temperature anomalies. There is anomalously low SLP over the Arctic with south-westerly winds in opposition to the climatological winter pattern of strong cold easterlies in the region from eastern Siberia east to northeastern Canada. There are also southerly wind anomalies feeding warm air north of Siberia. The previous warm spring period in Beringia from 1939-1941 (Fig. 11, left) does not show lower SLP anomalies over the Arctic. The 1953-55 SLP (Fig. 11, center) do show lower pressures in the central Arctic, again with warm anomalies in Siberia, Beringia, and eastern Canada. However, in 1953-55 the main center of action in SLP shifted to the western Arctic and away from the Atlantic, which is strong in the 1990s fields and the classical AO definition (Thompson and Wallace 1998). The surface pattern in the 1950s is similar to our spring pattern (B), whereas the pattern in the 1990s, follows spring pattern (A). Although the earlier temperature anomaly fields have some resemblance to the 1990s (spring pattern A), they can be understood as resulting from different low-level advection fields and are thus less likely to be part of a hemispheric-wide change similar to the 1990s (Shindell 2003).

In summary, there are five features shown in the visual inspection and PCA for spring: the generally cool temperature anomalies before 1920 with some local variability, the regional warming episodes near 1939-1941 and 1953-1955, the warm Siberian and Canadian temperatures in the 1970s, and the warm pan-Arctic temperatures of the 1990s.

\section{c. Summer, fall, and other months}

For summer, one would expect smaller anomalies in part because of increased importance of radiative processes and the melting of sea ice which can buffer temperature extremes near coastal stations. Hence note that the temperature anomaly scale on Fig. 12 for summer (July-August) is half that for the winter (Fig. 2) and spring (Fig. 8). In Scandinavia summer 
temperature anomalies are often reduced because the land-sea contrast is less compared to winter. Figure 12 shows that there are generally cool periods before 1910 in Scandinavia (Stns. 1-7) and before 1970 in much of Siberia eastward to NW Canada (Stns. 20-40). The strength of the warm anomalies in the 1930s through the 1950s from Baffin Bay eastward through western Siberia (Stns. 51-20) and cool anomalies for the rest of the Arctic are similar to those in winter data (Fig. 2) but are unlike those in the preceding spring. However, summer temperature anomalies in recent decades mirror spring warm anomalies from Siberia eastward to Canada (Stns. 16-49). PCAs of summer temperature anomalies are not shown as they had little large-scale temporal or spatial structure, presumably because of the small amplitudes and more local character compared with winter or spring.

Like spring the temperature anomalies of fall, as represented by October (Fig. 13), show strong longitudinal Arctic-wide covariability. Particularly strong are the warm anomalies from the mid 1930s to the early 1950s. This pattern is arguably repeated in the 1980/1990s but with more temporal variability at individual stations. E. Greenland eastward through Scandinavia (Stns. 54-7) was generally cool before 1930.

We have combined two months with similar anomaly patterns for winter (DecemberJanuary) and summer (July-August) and have used one month to represent spring and fall transitions. The following is a brief description of how the other six months relate to those shown; monthly plots are available at www.unaami.noaa.gov. Our four seasonal figures 2, 8, 12, 13 are in general representative of the variations for all months. February is similar to December/January except for a warming in north America in recent years. March is similar to April, only the intensity of the pattern is weaker. May and June are similar to April with cold historical temperatures in Scandinavia and warm temperatures across the Arctic in recent years. One difference is warmer historical temperatures in E. Greenland in May. September and November are much like October with warm Siberian and E. Greenland temperature anomalies from the late 1930s to early 1950s. In September there are warm anomalies in Baffin Bay and East Greenland regions in the 1920s. 


\section{Discussion}

\section{a. Comparison with previous PCAs}

All previous PCAs that we are aware of have been based on gridded fields of SAT. Walsh (1977) conducted a PCA analysis north of $60^{\circ} \mathrm{N}$ for $1955-1975$ from temperature anomalies for

all individual months. His first mode is the N. Atlantic seasaw and his second mode has a central Siberia and northern N. America in phase. Walsh's (1977) second mode echos our wintertime pattern (B). Kelley et al. (1982) uses annual data north of $60^{\circ} \mathrm{N}$ for $1881-1980$. Their first mode is an in phase behavior between Baffin Bay and Northern Siberia with the PC peaking in the late 1920s and 1930. Their second mode is a N. Atlantic seasaw. Semenov and Bengtsson (2003) use six month averages NDJFMA north of $40^{\circ} \mathrm{N}$ for $1892-1999$. Their first mode is the $\mathrm{N}$. Atlantic seasaw, and its PC becomes positive after 1970. Their second mode is a plus-minus hemispheric pattern with a high frequency character and potential ENSO influence. Their third mode shows a mid-century 1920-1955 warm period with Baffin Bay and Scandinavia in phase.

All analyses include the winter seasaw pattern as an early detected mode. Our winter pattern (A) time series stay interdecadal in character during the recent decade, while the Semenov and Bengtsson (2003) first PC shows an upward trend during the 1980-1990s. Perhaps their compositing of March-April, which does have this trend, with earlier winter months contributes to this result. Our third winter pattern (C) and first spring pattern (A) show mid-century warming events in the 1920-1930s and 1940-1950s, respectively. The Semenov and Bengtsson (2003) mid-century third PC also seems to composite these two seasonal events. The Kelly et al. (1982) results of an in phase behavior between Baffin Bay and Siberia in the 1930s support the conclusion of Semenov and Bengtsson (2003) that the character of the 1930s is separate from the NAO. This interpretation is reinforced by our winter pattern $(\mathrm{C})$; the Arctic temperature signal in the 1930 s is a separate mode (at least mathematically) from the interdecadal NAO, our winter pattern $(\mathrm{A})$. 


\section{b. Long-term behavior 1800-2002}

Except for winter in northern Europe and fall in central Siberia, all SAT records show a general warming over the period of record (Figs. 2, 8, 12, 13). That these trends are in nonwinter months is consistent with papers that suggest a reduction in volcanic influence from the mid 1800s through the 1950s. The upward trend of SAT has continued during recent decades despite an increase in volcanic forcing. Several authors suggest that this continued trend is due to anthropogenic forcing (d'Arrigo and Jacoby 1993; Free and Robock 1999, Fig. 7; Stott et al. 2001).

While cooling due to increased volcanic aerosols may be true for the non-winter months, several authors make a case for winter warming in Eurasia from an increase in volcanic eruptions (Robock and Mao 1992; Graf et al. 1993; Stenchikov et al. 2002). Robock and Mao (1992) note high latitude winter warming from the 12 largest volcanoes since 1883, also evident in our Fig. 2. The physical argument is that the radiational effects are large at low latitude, producing primarily a dynamical response in mid and high latitudes due to increased latitudinal temperature gradients. Thus the winter warming of the European sector in the 1930s, which influences the pan-Arctic annual average temperature anomalies, cannot be clearly attributed to the lack of vulcanism.

Certain previous references are noteworthy. Luterbacher et al. (2001) notes cool springs and summers in Europe for 1675-1715, related to a low AO period. They also note a weak Azores high pressure cell, suggesting earlier midlatitude influences on the Arctic. Gervais and MacDonald (2001) note that trees on the Kola peninsula show suppressed growth for a twentyyear period after the 1809 eruption. Lee et al. (2000) reports cold springs in Finland before 1900, while Ahlman (1948) notes an absence of a long term secular trend in summer temperatures in Scandinavia for the 19th and early 20th centuries. Førland et al. (1997) notes a long term upward trend in the Svalbard temperatures in spring. It is very likely that the Arctic was cold in certain decades in the 19th century: 1810s, 1830s, 1880s, with a warming rebound in the first half of the 20 th century. However, the winter warming in Europe in the 1930s-early 1940s appears to be 
more of a high latitude internal variability event (Bengtsson et al. 2003) following a warm phase of the N. Atlantic seasaw in the 1920s.

While there is a general minimum in temperature anomalies in the Arctic during the 1960-1970s, we see no clear evidence for a 50-year Low Frequency Oscillation (LFO) in SAT, as proposed by Polyakov et al. (2002), in the proxy data before 1920 (Briffa and Osborn 2002). That the physics for the mid-century warming may be different from the 1990s warm period (Hanssen-Bauer and Førland 1998; Bengtsson et al. 2003) is an additional argument against an LFO. Thus, there is no clear justification for extrapolating a 50-year cycle forward, as there is no clear extrapolation backward to the 1800s.

\section{c. Processes}

Temperature anomalies in the Arctic, at least in fall through spring, are primarily driven through temperature advection. This is documented for the Scandinavian sector in winter (Fu et al. 1999) and the remaining Arctic in spring (Overland et al. 2002). Thus the positive phase of the AO provides warming and cooling in the Atlantic sector but not a strong advective signal in the remainder of the Arctic in the winter (Rigor et al. 2002), but considerable advective warming in the remainder of the Arctic in the spring when the polar vortex breaks down. The strong dynamic (wind) control in the Arctic cool season suggests care should be taken in estimating annual temperatures from summer-based proxy data which are often controlled by radiational processes. It is also possible that sea ice processes and change in land cover, such as the increase in shrubs (Sturm et al. 2001) promote the persistence of spring and summer anomalies on decadal scales. Relating temperature and local wind patterns is insufficient, however; future work needs to focus on larger scale forcing of the upper atmospheric long wave patterns through changes in latitudinal temperature gradients.

We hypothesize the following conceptual model for Arctic change (Fig. 14). The figure is modified from Stenchikov et al. (2002), and is consistent with the modeling work of Shindell (2003). It represents processes of the troposphere and lower stratosphere from the North Pole to 
the subtropics. One of the most robust changes in the 1990s was the cold temperature anomalies in the northern lower stratosphere that led to a larger latitudinal temperature gradient and stronger polar vortex (IPCC Report 2001, page 121). Through the physics of the Arctic Oscillation (Thompson and Wallace 1998) this increase in the polar vortex is associated with increased warm air advection near the surface in the NE Atlantic sector in winter and NW North America in spring (Overland et al. 2002). Reduced low-level temperature gradients can provide a positive feedback to the polar vortex through decreased drag on lower stratospheric winds (EP fluxes) (Stenchikov et al. 2002), but this is a chaotic intraseasonal (Baldwin and Dunkerton 2001) process. However, changes in the Arctic, such as reduced sea ice and tundra area as well as from upper ocean heat storage and advection, can provide multi-year memory to the system. Such a decadal feedback signal could have occurred in the 1930s (Bengtsson et al. 2003). Ozone may reinforce the dynamic cooling of the Arctic stratosphere, especially in spring when it is important to the polar vortex dynamics (Newman et al. 2001). Radiation processes have their largest direct effect in the subtropics but force the subarctic circulation through latitudinal temperature gradients. Thus, at least for the cool season anomalies, the Arctic is most responsive to dynamic factors through changes in temperature advection, forced by subtropical radiative processes and stabilized by surface feedbacks.

\section{Conclusions}

There are considerable differences in decadal SAT variability in the Arctic across seasons and regions. These differences are apparent in both the visual and semi-quantitative (PCA) investigation of the data. Much previous work centers on annual, six month, and Arctic-wide averages (Kelley et al. 1982; Przbylak 2000; Polyakov et al. 2002; Semenov and Bengtsson 2003). However, investigating spatial patterns in annual data or temporal patterns in

longitudinally averaged data leads to considerable confounding of Arctic processes.

In hindsight our separating the PCA into three periods 1886-2002, 1912-2002, and 1936-2002 to understand the influence of historical station coverage is justified. The second 
EOF for the more recent 1936-2002 period was, for example, distinct from the other PCAs based on longer data periods. Using the larger amounts of recent station data to establish an EOF pattern, and then extrapolating earlier in time by projecting onto fewer stations to determine the PCs, is questionable.

In this study we have used PCA to track the major features shown in time/longitude plots of SAT. For example, the nearly Arctic-wide simultaneous events of the 1910s and 1980s are resolved by our winter pattern B. We also confirm the winter N. Atlantic seesaw pattern and that the mid 20th-century warming in winter is mathematically separable from this seasaw pattern in PCA. Our PCs differ somewhat from the previous multi-month composite analyses. Our analysis of winter pattern (A) emphasizes a continuing NAO interdecadal oscillation, and a separate warming represented by pattern (C) in the 1930s similar to Semenov and Bengtsson (2003). Our spring pattern (A) emphasizes warming in the 1940s/1950s and 1990s. However, based on the preponderance of the evidence, only spring in the 1990s and possibly the summer, show an Arctic-wide SAT signal, consistent with a pan-Arctic change in circulation patterns. It will be important to monitor this large-scale change over the next several decades.

Acknowledgments. We appreciate discussions with K. Wood, M. Wang, and N. Bond on aspects of this paper. We thank NSF through the SEARCH Project Office for support of this study. The paper is also a contribution to SEARCH through the NOAA Arctic Research Office. JISAO contribution number 997 under NOAA Cooperative Agreement NA17RJ1232. 


\section{REFERENCES}

Ahlmann, H. W., 1948: The present climate fluctuation. Geogr. J., 112, 165-195.

Ambaum, M. H. P., and B. J. Hoskins, 2002: The NAO troposphere-stratosphere connection. $J$. Climate, 15, 1969-1978.

Baldwin, M. P., and T. J. Dunkerton, 2001: Stratospheric harbingers of anomalous weather regimes. Science, 294, 581-584.

Bengtsson, L., V. A. Semenov, and O. Johannessen, 2003: The early century warming in the Arctic_a possible mechanism. Report 345 Max Planck Institut fur Meteorologie, ISSN 0937-1060, $31 \mathrm{pp}$.

Briffa, K. R., and T. J. Osborn, 2002: Blowing hot and cold. Science, 295, 2227-2228.

Chapman, W. L., and J. E. Walsh, 1993: Recent variations of sea ice and air temperature in high latitudes. Bull. Am. Meteorol. Soc., 74, 33-47.

Crowley, T. J., 2000: Causes of climate change over the past 1000 years. Science, 289, 270-277.

d'Arrigo, R. D., and G. C. Jacoby, 1993: Secular trends in high northern latitude temperature reconstructions based on tree rings. Clim. Change, 25, 163-177.

Davis, R. E., 1976: Predictability of sea temperature and sea level pressure anomalies over the North Pacific Ocean. J. Phys. Oceanogr., 6, 249-266.

Free, M., and A. Robock, 1999: Global warming in the context of the little ice age. J. Geophys. Res., 104, 19 057-19 070.

Førland, E. J., I. Hanssen-Bauer, and P. Nordli, 1997: Climate statistics and long-term series of temperature and precipitation at Svalbard and Jan Mayen. DNMI Report, 21/97 KLIMA, Oslo, $72 \mathrm{pp}$.

Fu, C., H. Diaz, D. Dong, and J. O. Fletcher, 1999: Changes in atmospheric circulation over northern hemisphere oceans associated with the rapid warming of the $1920 \mathrm{~s}$. Int. J. Climatol., 19, 581-606. 
Gervais, B. R., and G. M. MacDonald, 2001: Tree-ring and summer-temperature response to volcanic aerosol forcing at the northern tree-line, Kola Peninsula, Russia. The Holocene, 11, 499-505.

Graf, H. F., I. Kirchner, A. Robock, and I. Schult, 1993: Pinatubo eruption winter climate effects: model versus observation. Clim. Dyn., 9, 81-93.

Hanssen-Bauer, I., and E. J. Førland, 1998: Long-term trends in precipitation and temperature in the Norwegian Arctic: can they be explained by changes in atmospheric circulation patterns? Clim. Res., 10, 143-153.

IPCC Report, Houghton, J. T. and coauthors, 2001: Climate Change 2001: The scientific basis. Cambridge Press, Cambridge, UK, 881 pp.

Johannessen, O. M., and Coauthors, 2003: Arctic climate change—observed and modeled temperature and sea ice. Nansen Center Technical Report, 26 pp.

Jones, P. D., 1994: Hemispheric surface air temperature variations: A reanalysis and an update to 1993. J. Climate, 7, 1794-1802.

Kelly, D. M., and Coauthors, 1982: Variations in surface air temperatures: Pt 2, Arctic regions 1881-1980. Mon. Weather Rev., 110, 71-83.

Lee, S. E., M. C. Press, and J. A. Lee, 2000: Observed climate variations during the last 100 years in Lapland, Northern Finland. Int. J. Climatol., 20, 329-346.

Luterbacher, J., and Coauthors, 2001: The late maunder minimum (1675-1715)—A key period for studying decadal scale climate change in Europe. Clim. Change, 49, 441-462.

Moberg, A., H. Bergström, J. R. Krigsman, and O. Svanered, 2002: Clim. Change, 53, 171-212.

Moritz, R. E., C. M. Bitz, E. J. Steig, 2002: Science, 297, 1497-1502.

Newman, P. A., E. R. Nash, and J. E. Rosenfield, 2001: What controls the temperature of the Arctic stratosphere in spring? J. Geophys. Res., 106, 19 999-20 010.

Omstedt, A., and D. Chen, 2001: Influence of atmospheric circulation on the maximum ice extent in the Baltic Sea. J. Geophys. Res., 106, 4493-4500. 
Overland, J. E., M. Wang, and N. A. Bond, 2002: Recent temperature changes in the western Arctic during spring. J. Climate, 15, 1702-1716.

—, M. C. Spillane, and N. N. Soreide, 2003: Integrated analysis of physical and biological panArctic change. Clim. Change, in press.

Percival, D. B., and H. O. Mofjeld, 1997: Analysis of subtidal coastal sea level fluctuations using wavelets. J. Amer. Stat. Assoc., 92, 868-880.

Polyakov, I. V., and Coauthors, 2002: Observationally based assessment of polar amplification of global warming. Geophys. Res. Lett., 29, doi:10.1029/2001GL011111.

Przybylak, R, 2000: Temporal and spatial variation of surface air temperature over the instrumental observations in the Arctic. Int. J. Climatol., 20, 587-614.

-, 2002: Variability of Air Temperature and Atmospheric Precipitation in the Arctic. Kluwer, Dordrecht, $330 \mathrm{pp}$.

—, 2003: The Climate of the Arctic. Kluwer, Dordrecht, 270 pp.

Rigor, I. G., R. L. Colony, and S. Martin, 2000: Variations in surface air temperature observations in the Arctic 1979-1997. J. Climate, 13, 896-914.

—, J. M. Wallace, and R. L. Colony, 2002: Response of sea ice to the Arctic Oscillation. J. Climate, 15, 2648-2663.

Robock, A., 2000: Volcanic eruptions and climate. Rev. Geophys., 38, 191-219.

—, and J. Mao, 1992: The volcanic signal in surface temperature observations. J. Climate, 8 , $1086-1103$

Rogers, J. C., 1985: Atmospheric circulation changes associated with the warming over the northern North Atlantic in the 1920s. J. Climate Appl. Meteorol., 24, 1303-1310.

-, and E. Mosley-Thompson, 1995: Atlantic cyclones and the mild Siberian winters of the 1980s. Geophys. Res. Lett., 22, 799-802.

-, and M. J. McHugh, 2002: On the separability of the North Atlantic Oscillation and the Arctic Oscillation. Clim. Dyn., 19, 599-608. 
Semenov, V. A., and L. Bengtsson, 2003: Modes of the wintertime Arctic temperature variability. Max Planck Institut fur Meteorologie, Report 343, ISSN 0937-1060, 18 pp.

Serreze, M. C., and Coauthors, 2000: Observational evidence of recent change in the northern high-latitude environment. Clim. Change, 46, 159-207.

Skeie, P., 2000: Meridional flow variability over the Nordic seas in the Arctic Oscillation framework. Geophys. Res. Lett., 27, 2569-2572.

Shindell, D., 2003: Whither Arctic climate. Science, 299, 215-216.

Stenchikov, G., and Coauthors, 2002: Arctic Oscillation response to the 1991 Mount Pinatubo eruption: effects of the volcanic aerosols and ozone depletion. J. Geophys. Res., 107, doi:10.1029/2002JD002090.

Stott, P. A., and Coauthors, 2001: Attribution of twentieth century temperature change to natural and anthropogenic causes. Clim. Dyn., 17, 1-21.

Sturm, M., C. Racine, and K. Tape, 2001: Increasing shrub abundance in the Arctic. Nature, 411, $546-547$.

Tett, S. F. B., and Coauthors, 1999: Causes of 20th century temperature change near the earth's surface. Nature, 399, 569-572.

Thompson, D. W. J., and J. M. Wallace, 1998: The Arctic Oscillation signature in the wintertime geopotential height and temperature fields. Geophys. Res. Lett., 25, 1297-1300.

van Loon, H., and J. C. Rogers, 1978: The seasaw in winter temperatures between Greenland and northern Europe, Part 1: General description. Mon. Weather Rev., 106, 296-310.

Walsh, J. E., 1977: The incorporation of ice station data into a study of recent Arctic temperature fluctuations. Mon. Weather Rev., 105, 1527-1535. 


\section{Figure Captions}

1. Location map for 59 stations used in the study (See Table 1). Also indicated are approximate regional sectors: Scandinavia, Siberia, Beringia, NW Canada, Baffin Bay, and E Greenland. Smaller station numbers in italics denote stations used in the time/longitude plots but are excluded from the PCA analysis due to short records or geographic proximity.

2. Time/longitude plot of surface air temperature (SAT) anomalies for winter (December-January) relative to the 1961-1990 mean for each station. Note the evidence of an NAO interdecadal seesaw response in Scandinavia, warm Siberian temperatures in the 1940s, and more hemispheric warming in the 1980s. Temperatures were generally cold before 1920 outside of Scandinavia.

3. The first winter (December-January) pattern (A) is represented by the PCA analysis with records beginning in 1886, 1912, and 1936. The Empirical Orthogonal Functions (EOFs) are shown as amplitudes at station locations as a function of longitude. The three EOFs show a similar seesaw pattern with Scandinavia out of phase with the Baffin Bay region. The lower panel shows the Principal Component (PC) time series. Different lines (solid, dashed) represent the three starting times for the different realizations. The PCs do not have a long-term trend.

4. Multi-resolution analysis of the January monthly temperature record for Stockholm (bottom curve) based on the Haar maximal overlap discrete wavelet transform with symmetric boundary conditions; the time series is from Moberg et al. (2002). Note the weak upward trend in the low frequency curve (top) and the considerable energy in the interdecadal (8-year half cycle) decomposition during the 20th century. 
5. The second winter (December-January) pattern (B) is represented by EOF mode 2 for station data beginning 1912 and EOF mode 3 for data starting 1936; see Table 2. Note the broad positive signal with the exception of Baffin Bay.

6. SAT and SLP anomalies for December-January 1983-1985. The years correspond to the month of January. SAT data are from Climate Research Unit CPUT2.0 and the SLP data are from the Trenberth set at NCAR.

7. The third winter (December-January) pattern (C) based on EOF mode 3 for data beginning in 1912 and EOF mode 2 for data beginning in 1886. All patterns show an in phase behavior between Baffin Bay and the Scandinavia regions.

8. Time/longitude plot of temperature anomalies for spring (April) similar to Fig. 2. Note the strong spatial covariability of the fields with warm hemispheric temperatures in the 1990s and cool temperatures before 1920.

9. The first spring (April) pattern (A) is fit by the EOF mode 1 for the series beginning in 1886, 1912, and 1936. There is a general in-phase Arctic-wide behavior with the weakest impact in the North Atlantic. The PC shows the warm anomalies in the 1950s and 1990s.

10. The second spring (April) pattern (B) supported by EOF mode 2 for the three analysis periods, shows an out of phase behavior between Eurasia and the Beringia/North America regions.

11. Comparison maps of the April SAT anomalies and March-April (SLP) fields for 1939-41, 1953-55, and the warm years of the 1990s. While the temperature anomaly patterns are 
somewhat similar, their causes relate to different advective fields. The temperature fields are from the CPU T2.0 and the SLP fields from NCAR.

12. Time/longitude plots of temperature anomalies for summer (July-August) similar to Fig. 2. Note that the range of the color scale is half of the winter and spring plots (Figs. 2, 8).

13. Time/longitude plots of temperature anomalies for fall (October) similar to Fig. 2.

14. A hypothesized conceptual model of Arctic change. A chaotic polar vortex (AO) has a weak positive feedback through reduced low-level temperature gradients and the influence of dynamic cooling on ozone. The surface warming in the Arctic is stabilized by terrestrial, oceanic, and sea ice multi-year processes, while the system can be driven by latitudinal differences in radiative processes due to volcanic, carbon-dioxide, and solar forcing in the subtropics. 
Table 1. Surface Air Temperature (SAT) stations, north of $64^{\circ} \mathrm{N}$, at which lengthy monthly data records are available. The percent data and time span statistics are based on the entire record at the station and may vary between months.

\begin{tabular}{|c|c|c|c|c|c|c|c|}
\hline $\begin{array}{l}\text { Zonal } \\
\text { Order }\end{array}$ & Station & $\begin{array}{l}\text { WMO } \\
\text { ID }\end{array}$ & $\begin{array}{l}\text { East } \\
\text { Lon. }\end{array}$ & $\begin{array}{l}\text { North } \\
\text { Lat. }\end{array}$ & Time Span & $\begin{array}{l}\text { Percent } \\
\text { Data }\end{array}$ & Locale \\
\hline 1 & Bodo Vi & 01152 & 14.4 & 67.3 & 1868:2002 & 100.0 & Water \\
\hline 2 & Svalbard* & 01008 & 15.5 & 78.3 & 1912:2002 & 97.8 & Polar desert \\
\hline 3 & Tromso & 01025 & 18.9 & 69.7 & 1856:2002 & 100.0 & Tundra \\
\hline 4 & Bjornoya & 01028 & 19.0 & 74.5 & 1949:2002 & 99.5 & Water \\
\hline 5 & Karesuando & 02080 & 21.5 & 68.5 & 1881:2002 & 100.0 & Wooded tundra \\
\hline 6 & Haparanda & 02196 & 24.1 & 65.8 & 1860:2002 & 99.9 & Coastal edges \\
\hline 7 & Vardo & 01098 & 31.1 & 70.4 & 1829:2002 & 87.9 & Water \\
\hline 8 & Ostrov Victoria & 20026 & 36.8 & 80.2 & 1959:1995 & 93.2 & Water \\
\hline 9 & Arhangelsk & 22550 & 40.7 & 64.5 & $1813: 2002$ & 80.4 & Main taiga \\
\hline 10 & Kanin Nos & 22165 & 43.3 & 68.7 & 1915:2002 & 94.3 & Water \\
\hline 11 & Nagurskoye & 20034 & 47.6 & 80.8 & 1952:1995 & 98.9 & Water \\
\hline 12 & Malye Karmakuly & 20744 & 52.7 & 72.4 & 1897:1999 & 90.6 & Tundra \\
\hline 13 & Narjan-Mar & 23205 & 53.0 & 67.6 & 1926:2002 & 97.7 & Tundra \\
\hline 14 & Ostrov Rudolfa & 20049 & 58.0 & 81.8 & 1932:1995 & 85.8 & Water \\
\hline 15 & Mys Zelanija & 20353 & 63.6 & 77.0 & 1931:1996 & 98.7 & Polar desert \\
\hline 16 & Salehard & 23330 & 66.7 & 66.5 & 1882:2002 & 98.6 & Bogs/woods \\
\hline 17 & Ostrov Belyj & 20667 & 70.1 & 73.3 & 1933:2001 & 97.1 & Water \\
\hline 18 & Ostrov Dikson & 20674 & 80.4 & 73.5 & 1916:2002 & 96.6 & Water \\
\hline 19 & Turuhansk & 23472 & 87.9 & 65.8 & 1880:2002 & 95.7 & Northern taiga \\
\hline 20 & Mys Golomianny & 20087 & 90.6 & 79.6 & 1930:2002 & 90.6 & Water \\
\hline 21 & Tura & 24507 & 100.2 & 64.3 & 1928:2002 & 97.9 & Main taiga \\
\hline 22 & Khatanga & 20891 & 102.5 & 72.0 & 1929:2002 & 92.6 & Wooded tundra \\
\hline 23 & O. Preobrazhenia & 21504 & 112.9 & 74.7 & 1934:1996 & 98.3 & Water \\
\hline 24 & Bukhta Tiksi & 21824 & 128.9 & 71.6 & 1932:2002 & 96.9 & Water \\
\hline 25 & Verhojansk & 24266 & 133.4 & 67.6 & 1885:2002 & 96.5 & Northern taiga \\
\hline 26 & Ostrov Kotelnyj & 21432 & 137.9 & 76.0 & 1933:2002 & 91.7 & Polar desert \\
\hline 27 & Mys Salaurova & 21647 & 143.2 & 73.2 & 1928:2001 & 96.1 & Water \\
\hline 28 & Zyrjanka & 25400 & 150.9 & 65.7 & 1935:2002 & 98.8 & Northern taiga \\
\hline 29 & Bukhta Ambarchik & 25034 & 162.3 & 69.6 & 1935:1999 & 98.8 & Water \\
\hline 30 & Anadyr & 25563 & 177.6 & 64.8 & 1898:2002 & 92.0 & Tundra \\
\hline 31 & Mys Shmidta & 25173 & 180.6 & 68.9 & 1932:2002 & 95.0 & Tundra \\
\hline 32 & Ostrov Vrangel & 21982 & 181.5 & 71.0 & 1926:2002 & 96.9 & Water \\
\hline 33 & Bukhta Providenia & 25594 & 186.8 & 64.4 & 1934:2002 & 96.0 & Tundra \\
\hline 34 & Mys Uelen & 25399 & 190.2 & 66.2 & 1918:2002 & 84.6 & Water \\
\hline 35 & Nome & 70200 & 194.6 & 64.5 & 1906:2002 & 98.7 & Water \\
\hline 36 & Barrow & 70026 & 203.2 & 71.3 & 1893:2002 & 100.0 & Tundra \\
\hline 37 & Fairbanks & 70261 & 212.1 & 64.8 & 1904:2002 & 98.7 & Main taiga \\
\hline 38 & Inuvik & 71957 & 226.5 & 68.3 & 1892:2002 & 84.5 & Tundra \\
\hline
\end{tabular}


Table 1. (continued).

\begin{tabular}{clcccccl}
\hline $\begin{array}{c}\text { Zonal } \\
\text { Order }\end{array}$ & Station & $\begin{array}{c}\text { WMO } \\
\text { ID }\end{array}$ & $\begin{array}{c}\text { East } \\
\text { Lon. }\end{array}$ & $\begin{array}{c}\text { North } \\
\text { Lat. }\end{array}$ & Time Span & $\begin{array}{c}\text { Percent } \\
\text { Data }\end{array}$ & Locale \\
\hline 39 & Norman Wells & 71043 & 233.2 & 65.3 & $1898: 2002$ & 95.2 & Main taiga \\
40 & Sachs Harbour & 71051 & 234.7 & 72.0 & $1955: 2002$ & 94.4 & Water \\
41 & Mould Bay & 71072 & 240.7 & 76.2 & $1948: 2000$ & 99.1 & Water \\
42 & Coppermine & 71938 & 244.9 & 67.8 & $1930: 2002$ & 96.6 & Tundra \\
43 & Cambridge Bay & 71925 & 254.9 & 69.1 & $1929: 2002$ & 87.7 & Tundra \\
44 & Baker Lake & 71926 & 263.9 & 64.3 & $1946: 2002$ & 94.0 & Tundra \\
45 & Resolute & 71924 & 265.0 & 74.7 & $1947: 2002$ & 97.9 & Tundra \\
46 & Eureka & 71917 & 274.1 & 80.0 & $1947: 2002$ & 97.9 & Water \\
47 & Pond Inlet & 71095 & 282.0 & 72.7 & $1922: 2002$ & 77.4 & Tundra \\
48 & Cape Dorset & 71910 & 283.5 & 64.2 & $1927: 2002$ & 83.7 & Water \\
49 & Frobisher Bay & 71909 & 291.4 & 63.8 & $1913: 2002$ & 89.0 & Tundra \\
50 & Alert & 71082 & 297.7 & 82.5 & $1950: 2002$ & 96.4 & Polar desert \\
51 & Upernavik & 04210 & 303.8 & 72.8 & $1873: 2002$ & 98.8 & Water \\
52 & Godthab Nuuk & 04250 & 308.2 & 64.2 & $1866: 2002$ & 98.0 & Tundra \\
53 & Egedesminde $\dagger$ & 04220 & 308.9 & 69.2 & $1866: 2002$ & 98.2 & Water \\
54 & Angmagssalik & 04360 & 322.4 & 65.6 & $1895: 2002$ & 98.5 & Water \\
55 & Kap Tobin & 04339 & 338.0 & 70.5 & $1931: 2002$ & 64.8 & Water \\
56 & Stykkisholmur & 04013 & 337.3 & 65.1 & $1846: 2002$ & 96.6 & Tundra \\
57 & Reykjavik & 04030 & 338.1 & 64.1 & $1901: 2002$ & 99.7 & Cool grass \\
58 & Station Nord & 04312 & 343.3 & 81.6 & $1952: 2002$ & 77.5 & Ice \\
59 & Jan Mayen & 01001 & 351.3 & 70.9 & $1921: 2002$ & 99.0 & Water \\
& & & & & & \\
\hline
\end{tabular}

*The Svalbard series is an amalgam of Istfjord Radio (WMO\#01005 1912-1980) and the continuing Svalbard Lufthavn record, 1977-Present.

$\dagger$ The Egedesminde series combines Jakobshavn (WMO\#04221 1866-1980) data with the continuing Egedesminde record, 1949-Present. 
Table 2. This table shows which EOF modes map onto which patterns for winter (December-January) for the three separate analyses with different length of data.

\begin{tabular}{llccc}
\hline & & \multicolumn{3}{c}{ Record Period } \\
\cline { 3 - 5 } & Description & 1880-2002 & $1912-2002$ & $1936-2002$ \\
\hline Pattern A & N Atlantic seesaw & mode 1 & mode 1 & mode 1 \\
Pattern B & 1980s warming & - & mode 2 & mode 3 \\
Pattern C & Baffin Bay/Siberia in phase & mode 2 & mode 3 & - \\
\hline
\end{tabular}




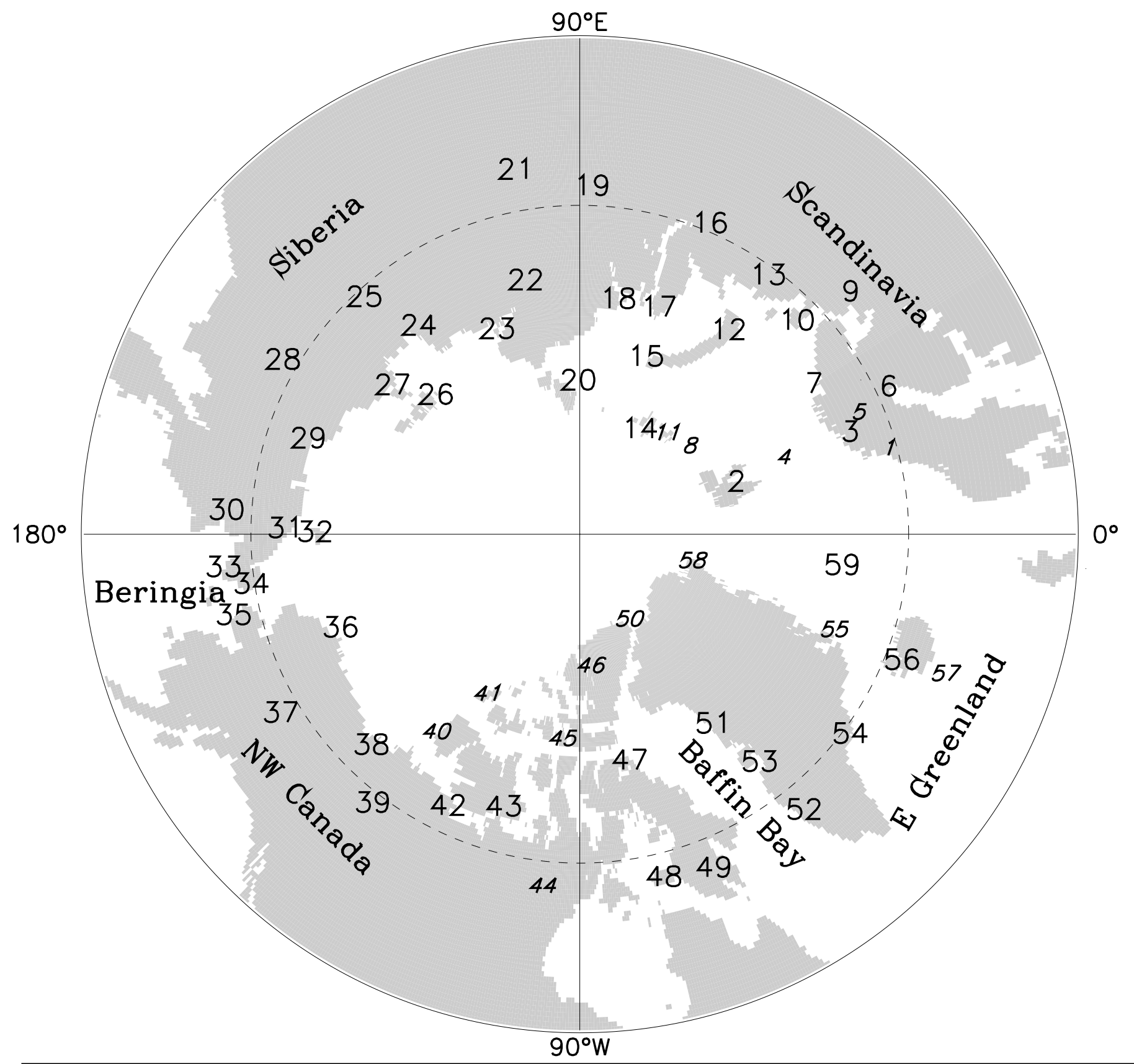

Figure 1 Location map for 59 stations used in the study (See Table 1). Also indicated are approximate regional sectors:

Scandinavia, Siberia, Beringia, NW Canada, Baffin Bay, and E Greenland. Smaller station numbers in italics denote stations used in the time/longitude plots but are excluded from the PCA analysis due to short records or geographic proximity. 
$0^{\circ} \mathrm{E} \quad 30^{\circ} \mathrm{E} \quad 60^{\circ} \mathrm{E} \quad 90^{\circ} \mathrm{E} \quad 120^{\circ} \mathrm{E} \quad 150^{\circ} \mathrm{E} \quad 180^{\circ} \quad 150^{\circ} \mathrm{W} \quad 120^{\circ} \mathrm{W} \quad 90^{\circ} \mathrm{W} \quad 60^{\circ} \mathrm{W} \quad 30^{\circ} \mathrm{W} \quad 0^{\circ} \mathrm{E}$

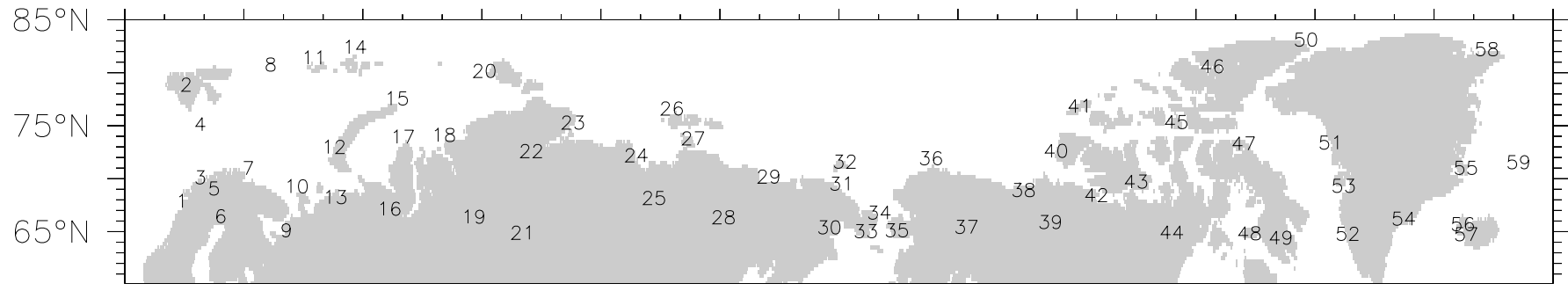

$357911131517192123252729313335373941434547495153555759^{\circ} \mathrm{C}$

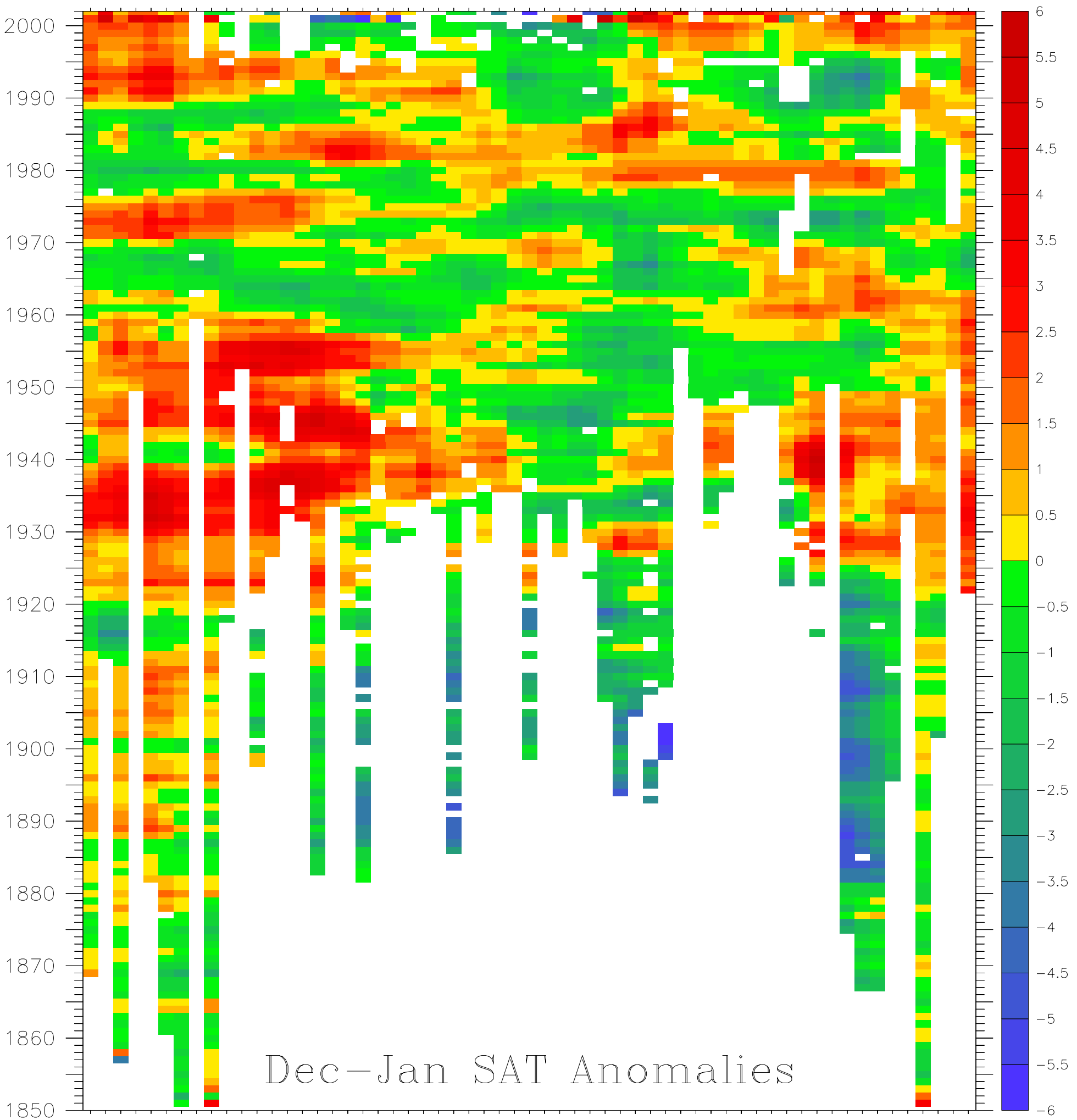

Figure 2

Time/longitude plot of surface air temperature (SAT) anomalies for winter (December-January) relative to the 1961-1990 mean for each station. Note the evidence of an NAO interdecadal seesaw response in Scandinavia, warm Siberian temperatures in the 1940s, and more hemispheric warming in the 1980s. Temperatures were generally cold before 1920 outside of Scandinavia. 

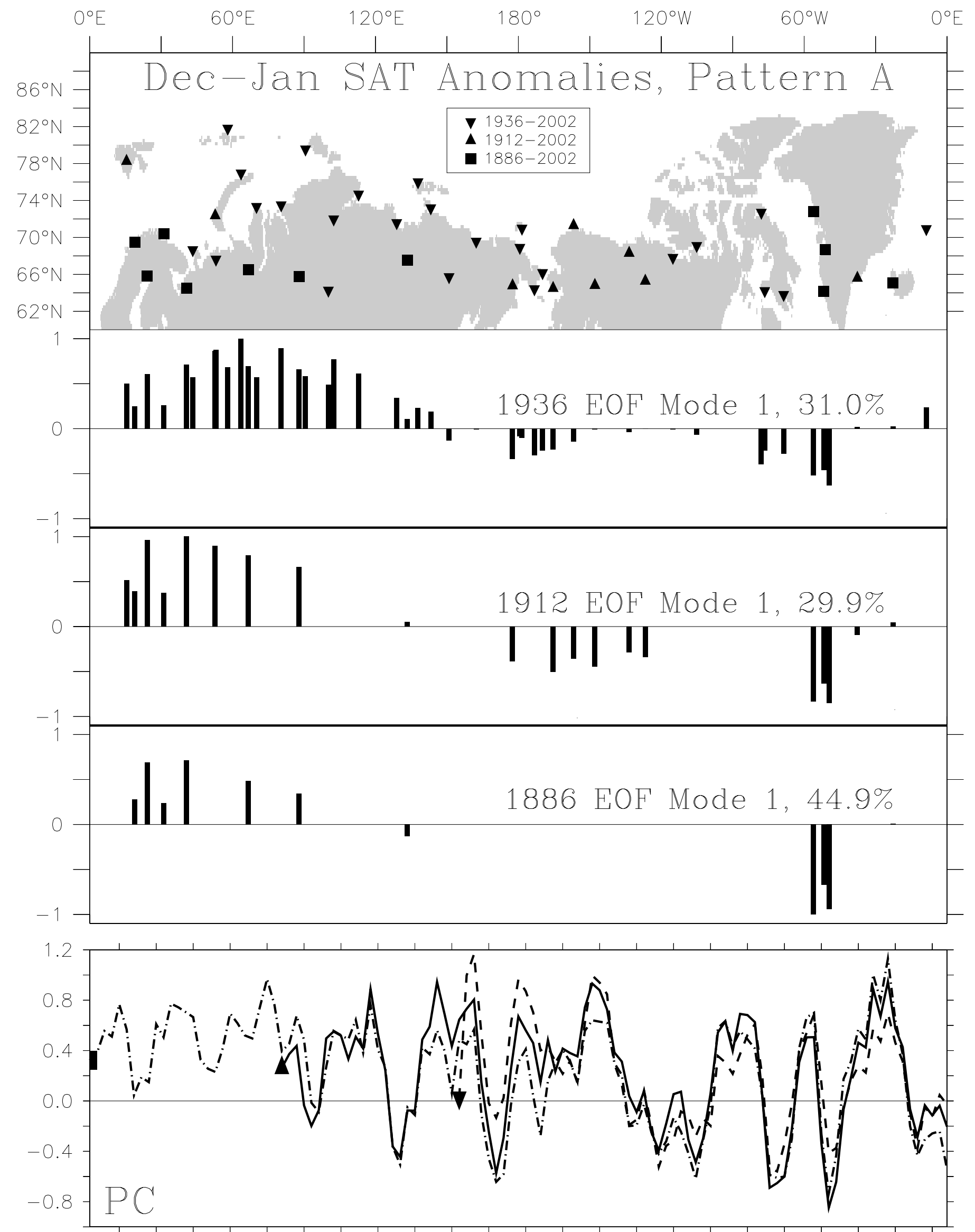

$\begin{array}{llllllllllll}1890 & 1900 & 1910 & 1920 & 1930 & 1940 & 1950 & 1960 & 1970 & 1980 & 1990 & 2000\end{array}$

The first winter (December-January) pattern (A) is represented by the PCA analysis with records beginning in 1886, 1912, and 1936. The Empirical Orthogonal Functions (EOFs) are shown as amplitudes at station locations as a function of longitude. The three EOFs show a similar seesaw pattern with Scandinavia out of phase with the Baffin Bay region. The lower panel shows the Principal Component (PC) time series. Different lines (solid, dashed) represent the three starting times for the different realizations. The PCs do not have a long-term trend. 


\section{Nominal Pass}

Band
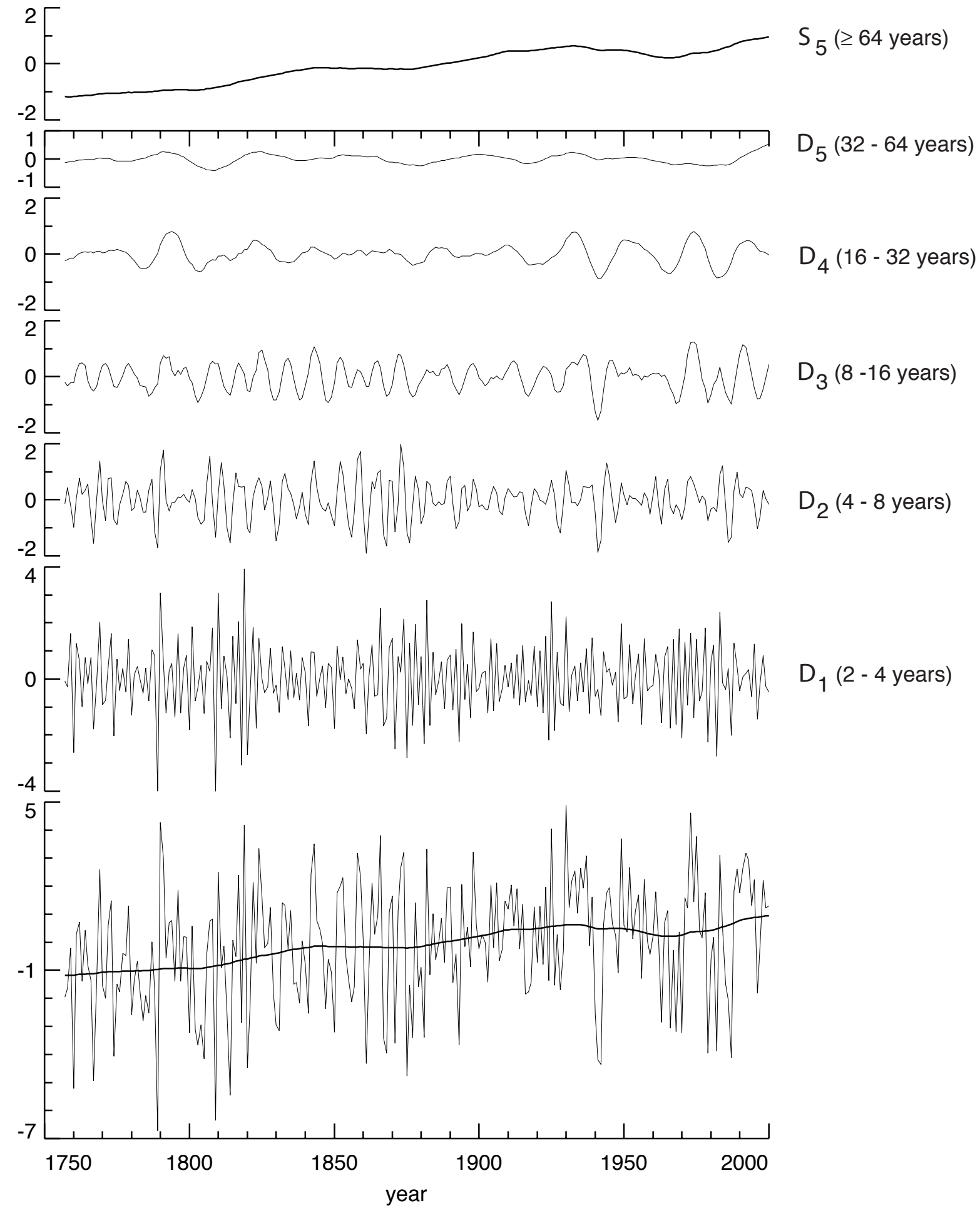

Figure 4 Multi-resolution analysis of the January monthly temperature record for Stockholm (bottom curve) based on the Haar maximal overlap discrete wavelet transform with symmetric boundary conditions; the time series is from Moberg et al. (2002). Note the weak upward trend in the low frequency curve (top) and the considerable energy in the interdecadal (8-year half cycle) decomposition during the 20th century. 

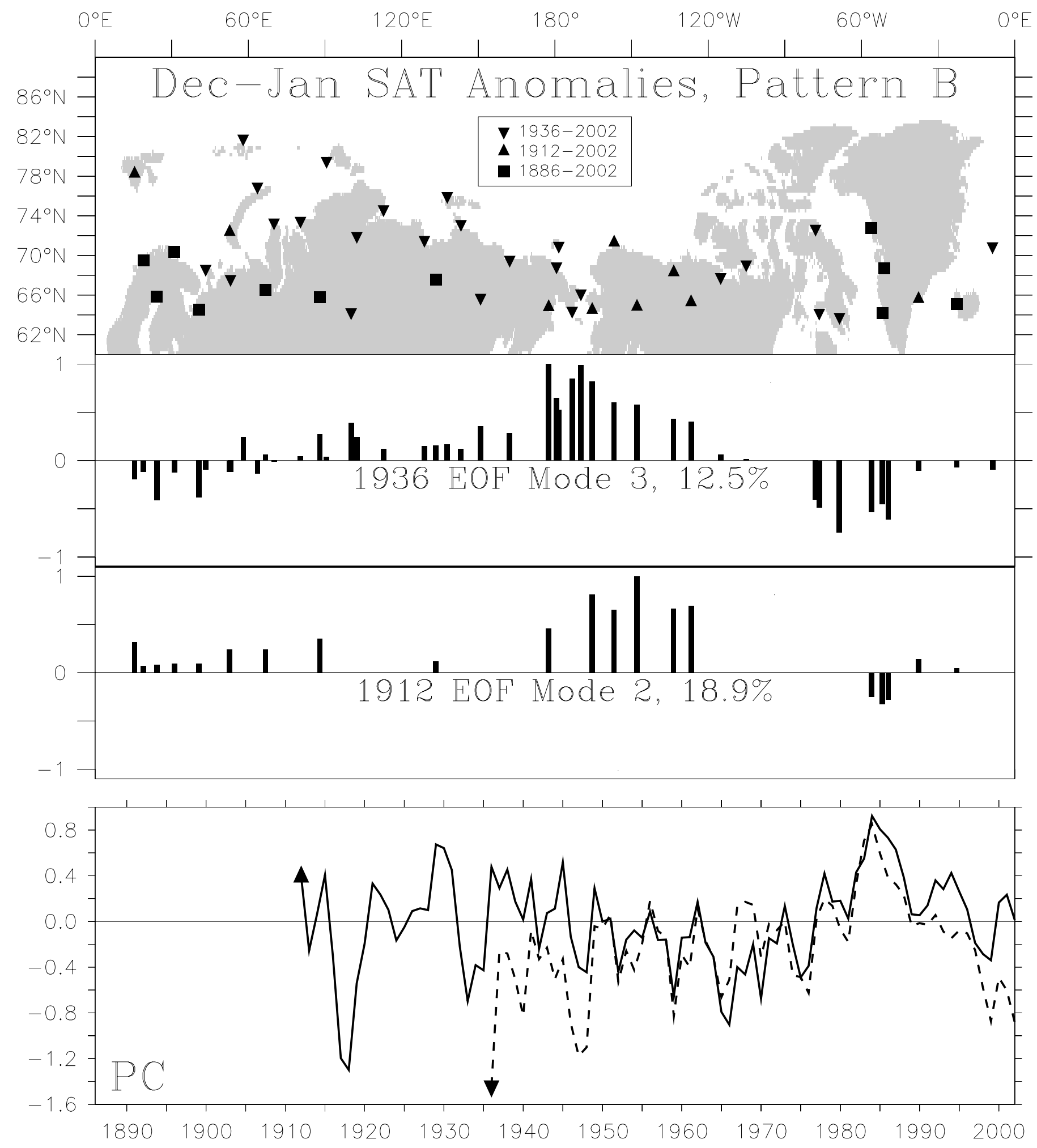

Figure 5 The second winter (December-January) pattern (B) is represented by EOF mode 2 for station data beginning 1912 and EOF mode 3 for data starting 1936; see Table 2. Note the broad positive signal with the exception of Baffin Bay. 

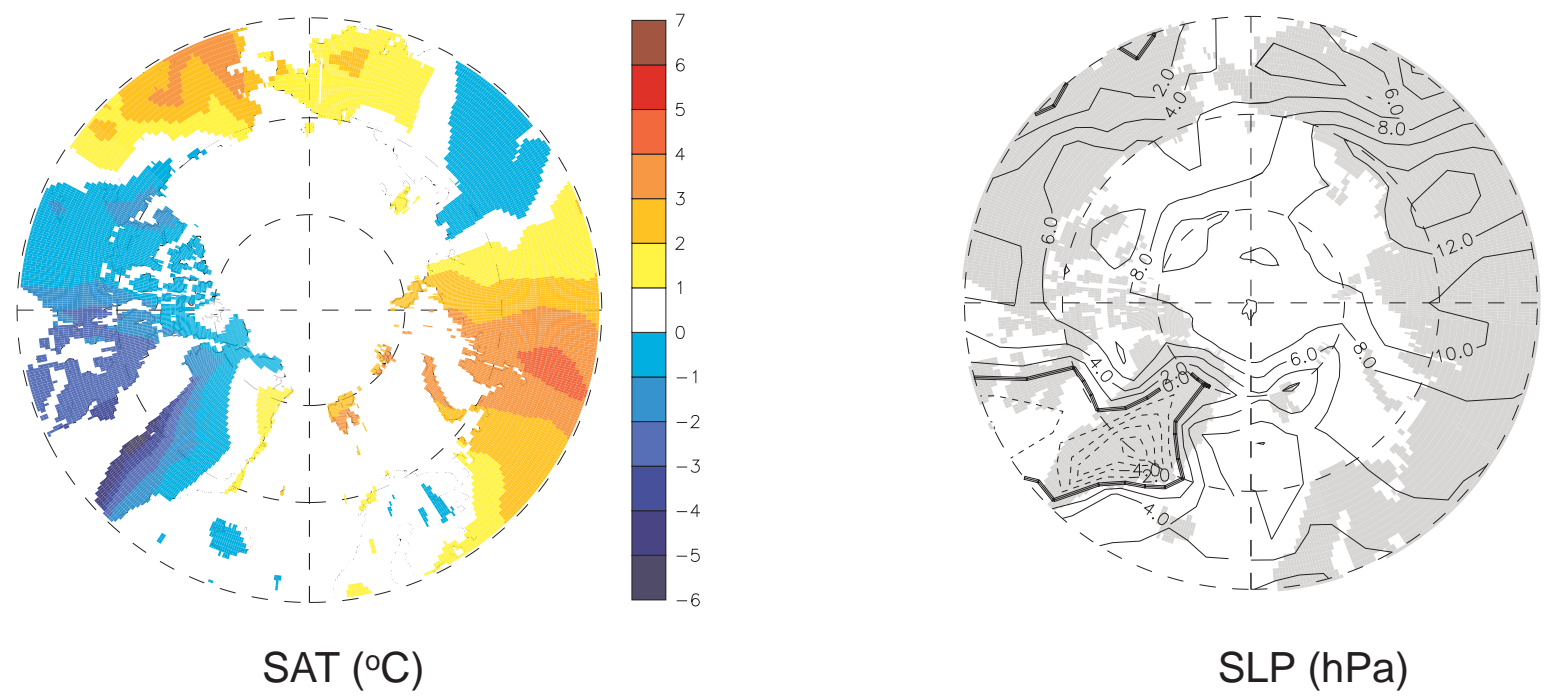

Figure 6

SAT and SLP anomalies for December-January 1983-1985. The years correspond to the month of January. SAT data are from Climate Research Unit CPUT2.0 and the SLP data are from the Trenberth set at NCAR. 

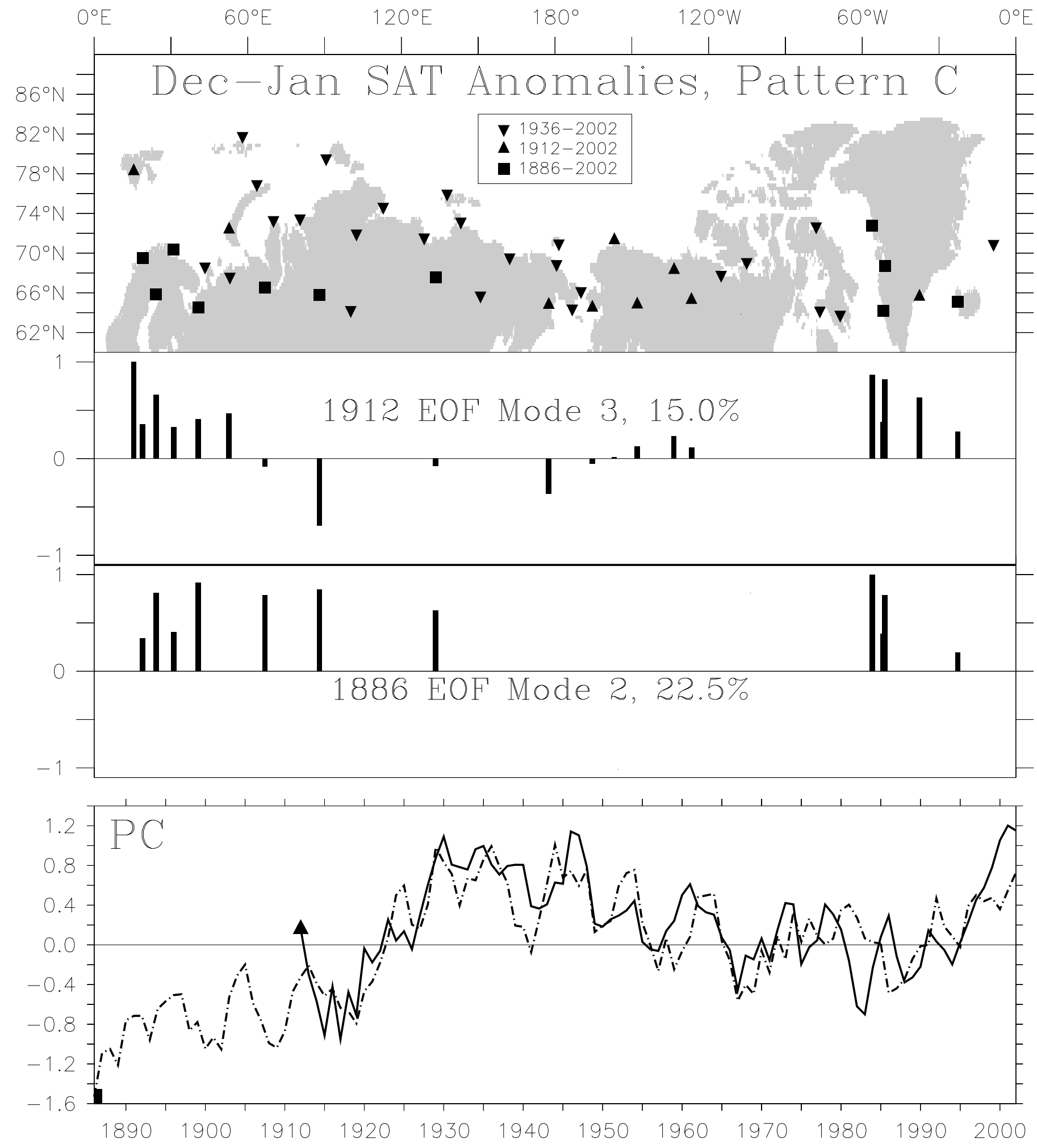

Figure 7 The third winter (December-January) pattern (C) based on EOF mode 3 for data beginning in 1912 and EOF mode 2 for data beginning in 1886. All patterns show an in phase behavior between Baffin Bay and the Scandinavia regions. 
$0^{\circ} \mathrm{E} \quad 30^{\circ} \mathrm{E} \quad 60^{\circ} \mathrm{E} \quad 90^{\circ} \mathrm{E} \quad 120^{\circ} \mathrm{E} \quad 150^{\circ} \mathrm{E} \quad 180^{\circ} \quad 150^{\circ} \mathrm{W} 120^{\circ} \mathrm{W} \quad 90^{\circ} \mathrm{W} \quad 60^{\circ} \mathrm{W} \quad 30^{\circ} \mathrm{W} \quad 0^{\circ} \mathrm{E}$

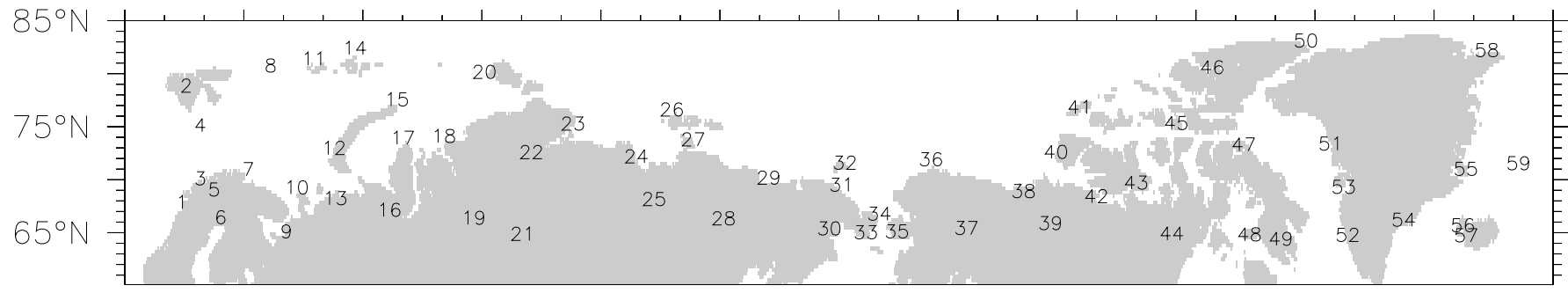

357911131517192123252729313335373941434547495153555759

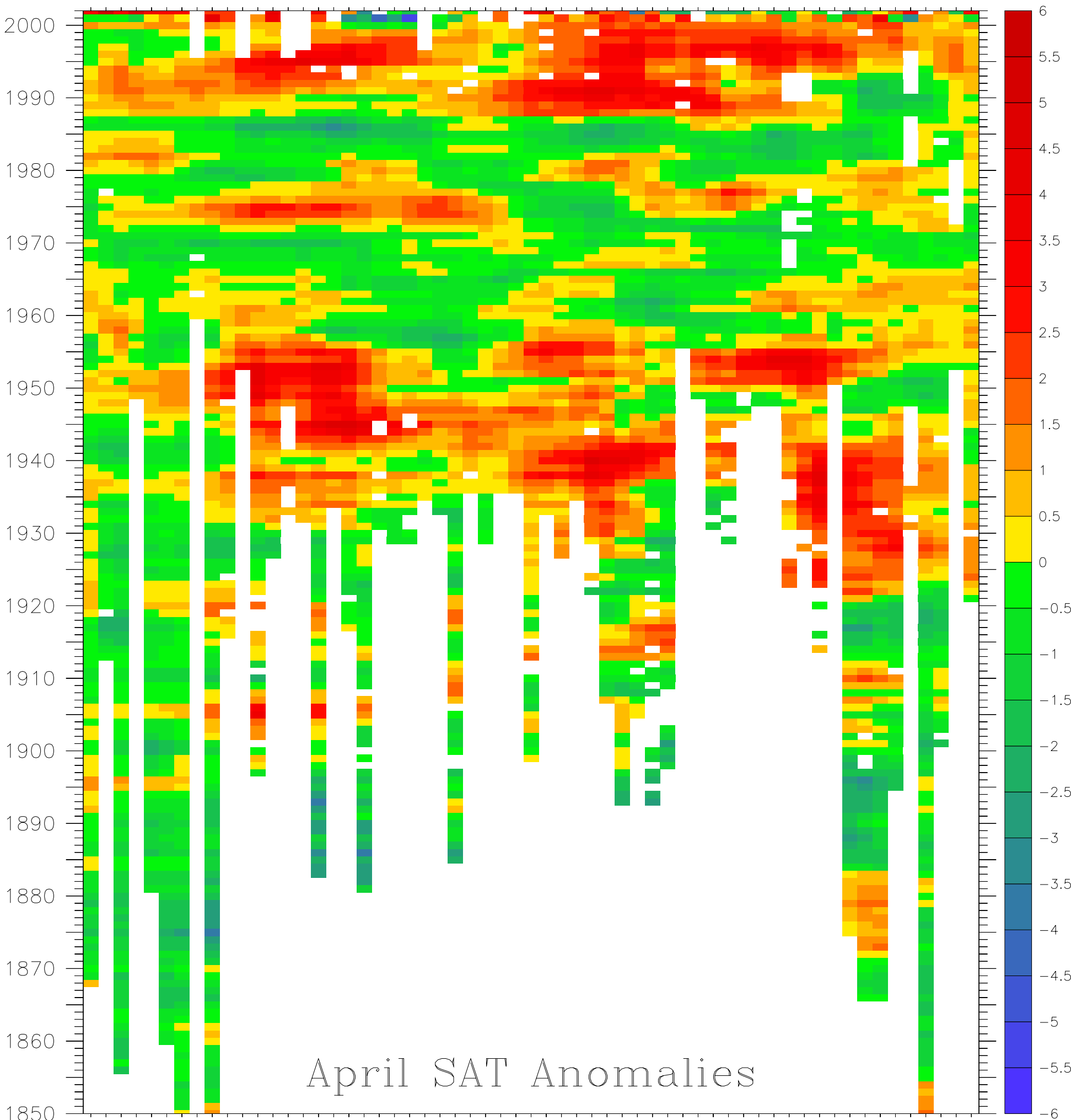



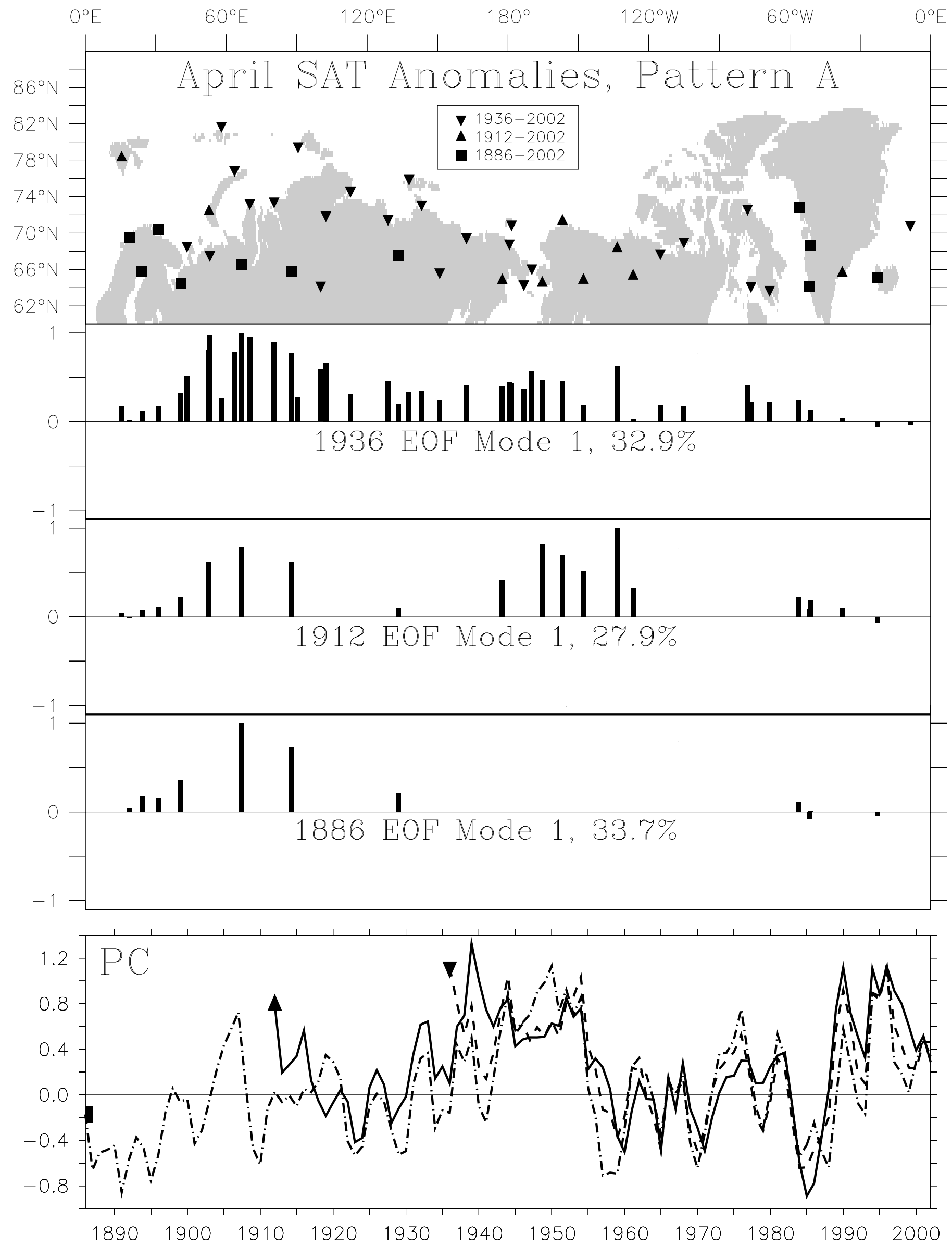

Figure 9 The first spring (April) pattern (A) is fit by the EOF mode 1 for the series beginning in 1886, 1912, and 1936. There is a general in-phase Arctic-wide behavior with the weakest impact in the North Atlantic. The PC shows the warm anomalies in the 1950s and 1990s. 

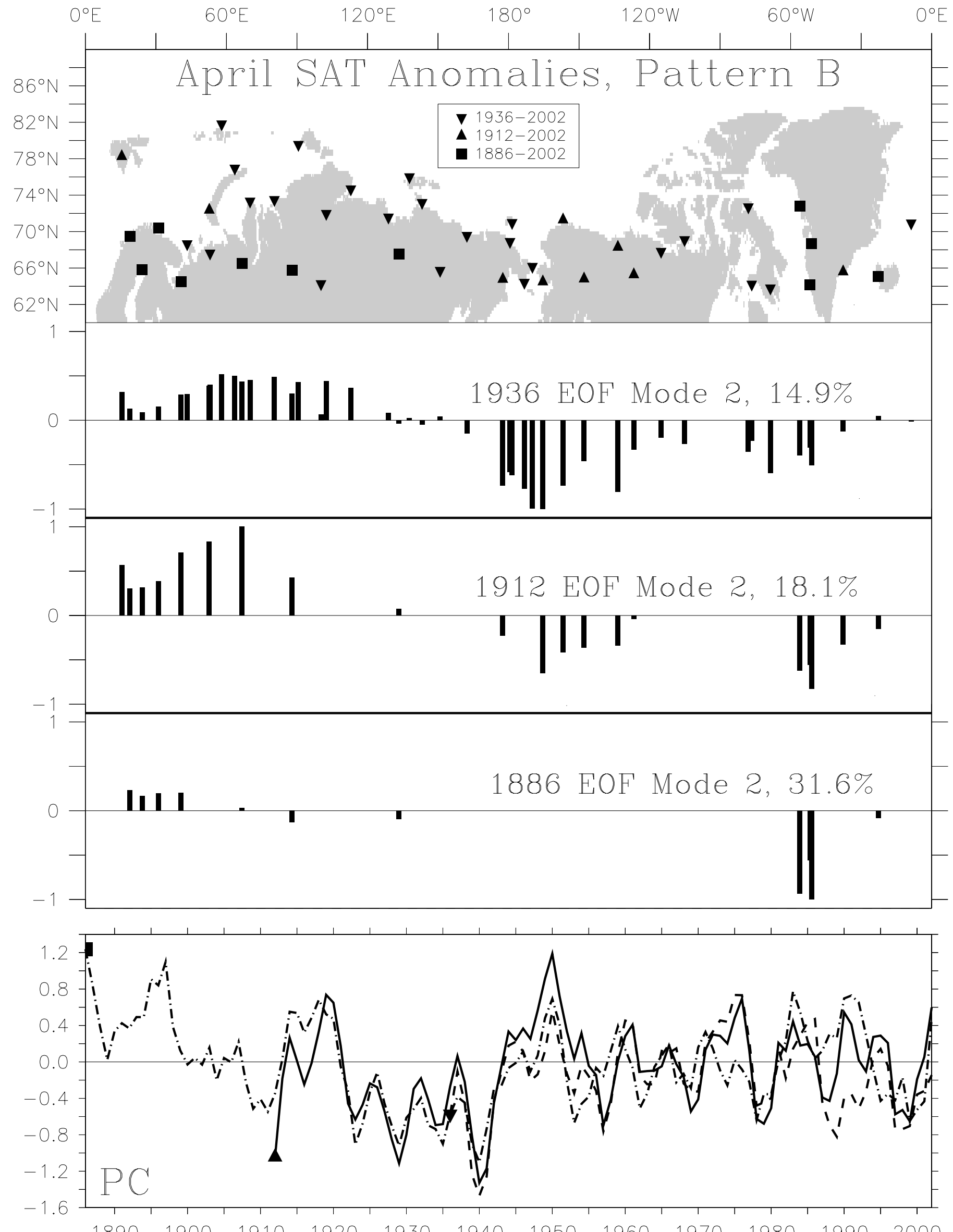

Figure 10 The second spring (April) pattern (B) supported by EOF mode 2 for the three analysis periods, shows an out of phase behavior between Eurasia and the Beringia/North America regions. 


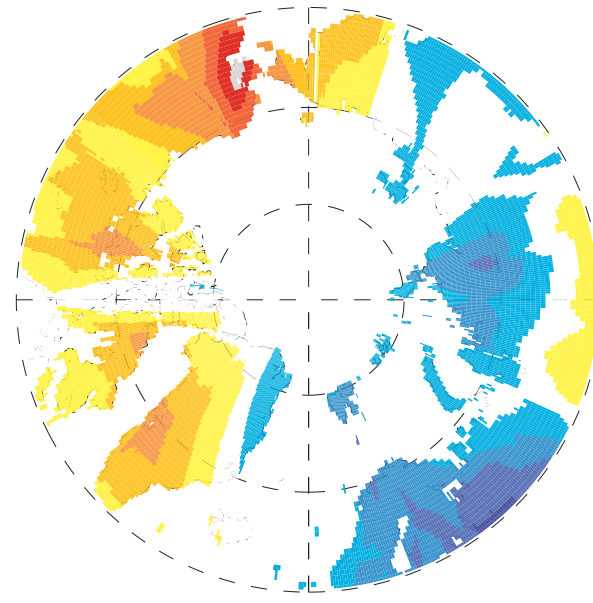

Composite of April SAT Anomalies $\left({ }^{\circ} \mathrm{C}\right)$
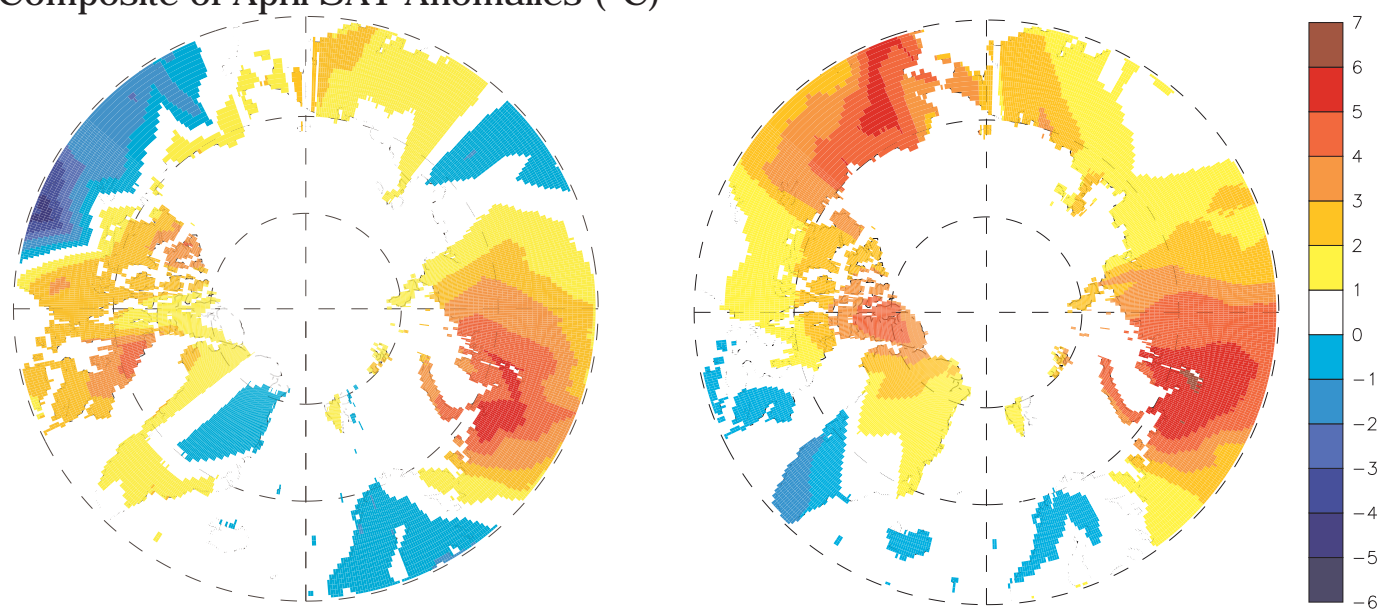

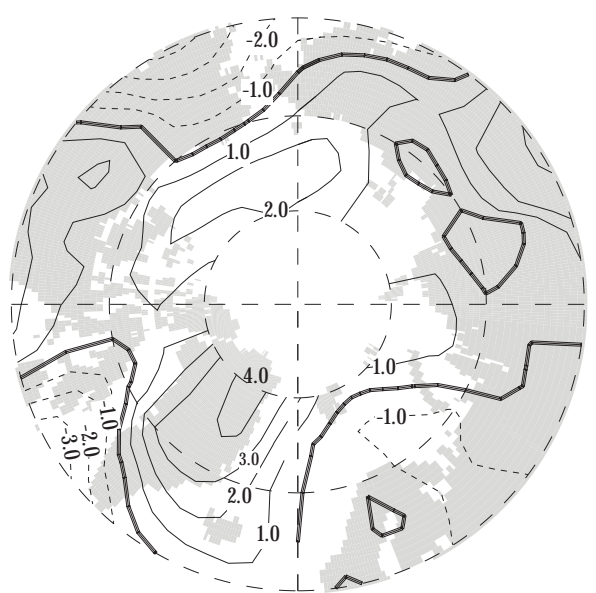

$1939-41$
Composite of Mar-Apr SLP Anomalies (hPa)

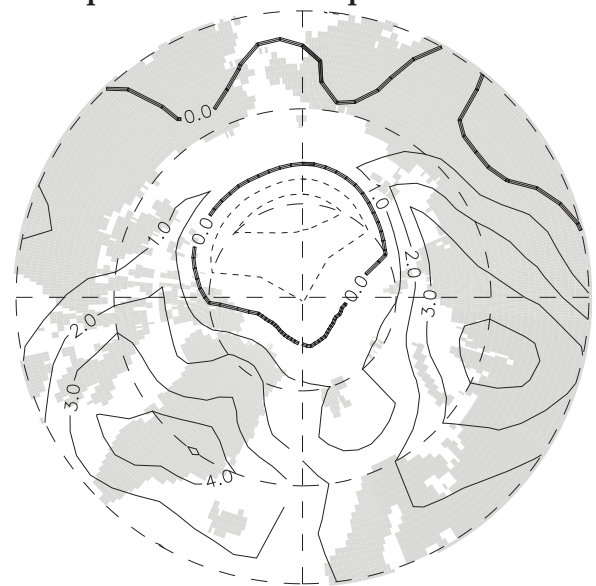

1953-55

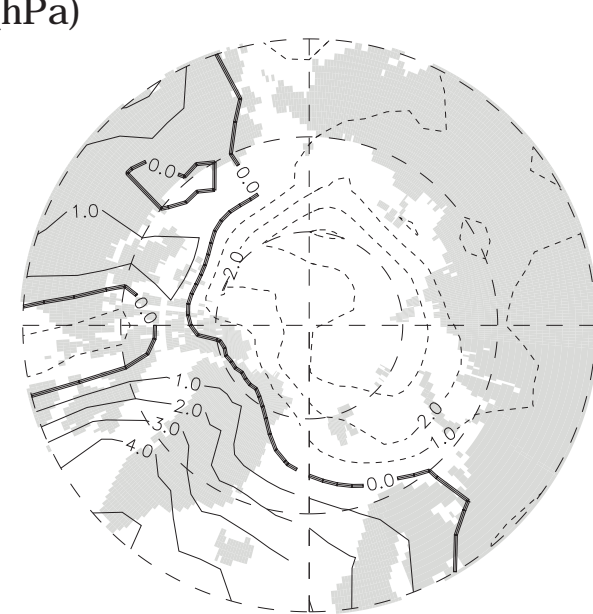

$1990,93,95,97$

Figure 11 Comparison maps of the April SAT anomalies and March-April (SLP) fields for 1939-41, 1953-55, and the warm years of the 1990s. While the temperature anomaly patterns are somewhat similar, their causes relate to different advective fields. The temperature fields are from the CPU T2.0 and the SLP fields from NCAR. 
$0^{\circ} \mathrm{E} \quad 30^{\circ} \mathrm{E} \quad 60^{\circ} \mathrm{E} \quad 90^{\circ} \mathrm{E} \quad 120^{\circ} \mathrm{E} \quad 150^{\circ} \mathrm{E} \quad 180^{\circ} \quad 150^{\circ} \mathrm{W} 120^{\circ} \mathrm{W} \quad 90^{\circ} \mathrm{W} \quad 60^{\circ} \mathrm{W} \quad 30^{\circ} \mathrm{W} \quad 0^{\circ} \mathrm{E}$

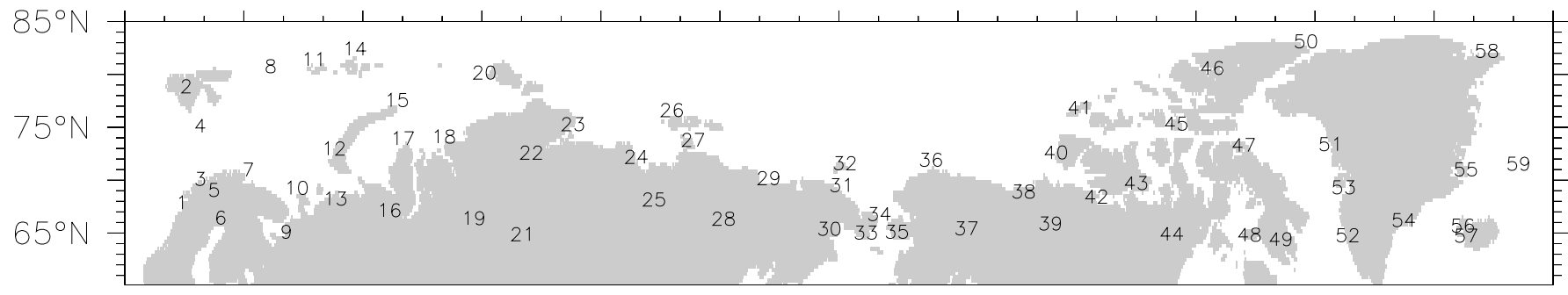

$1357911131517192123252729313335373941434547495153555759{ }^{\circ} \mathrm{C}$

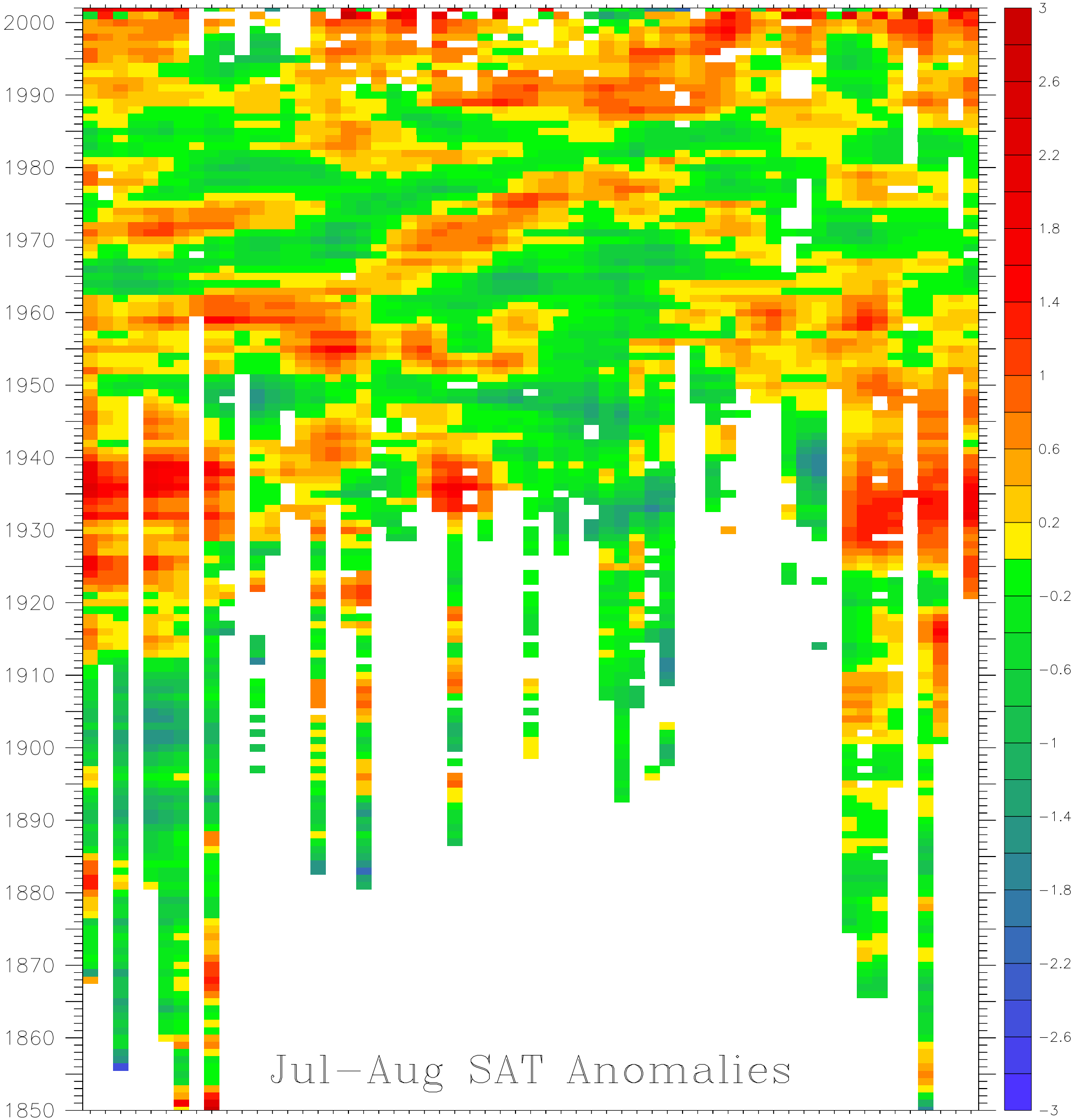


$0^{\circ} \mathrm{E} \quad 30^{\circ} \mathrm{E} \quad 60^{\circ} \mathrm{E} \quad 90^{\circ} \mathrm{E} \quad 120^{\circ} \mathrm{E} \quad 150^{\circ} \mathrm{E} \quad 180^{\circ} \quad 150^{\circ} \mathrm{W} 120^{\circ} \mathrm{W} \quad 90^{\circ} \mathrm{W} \quad 60^{\circ} \mathrm{W} \quad 30^{\circ} \mathrm{W} \quad 0^{\circ} \mathrm{E}$

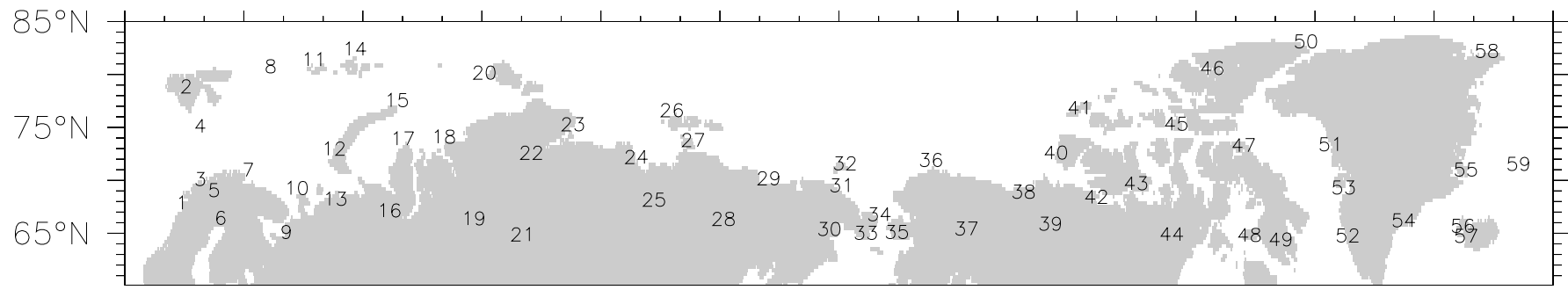

$357911131517192123252729313335373941434547495153555759{ }^{\circ} \mathrm{C}$

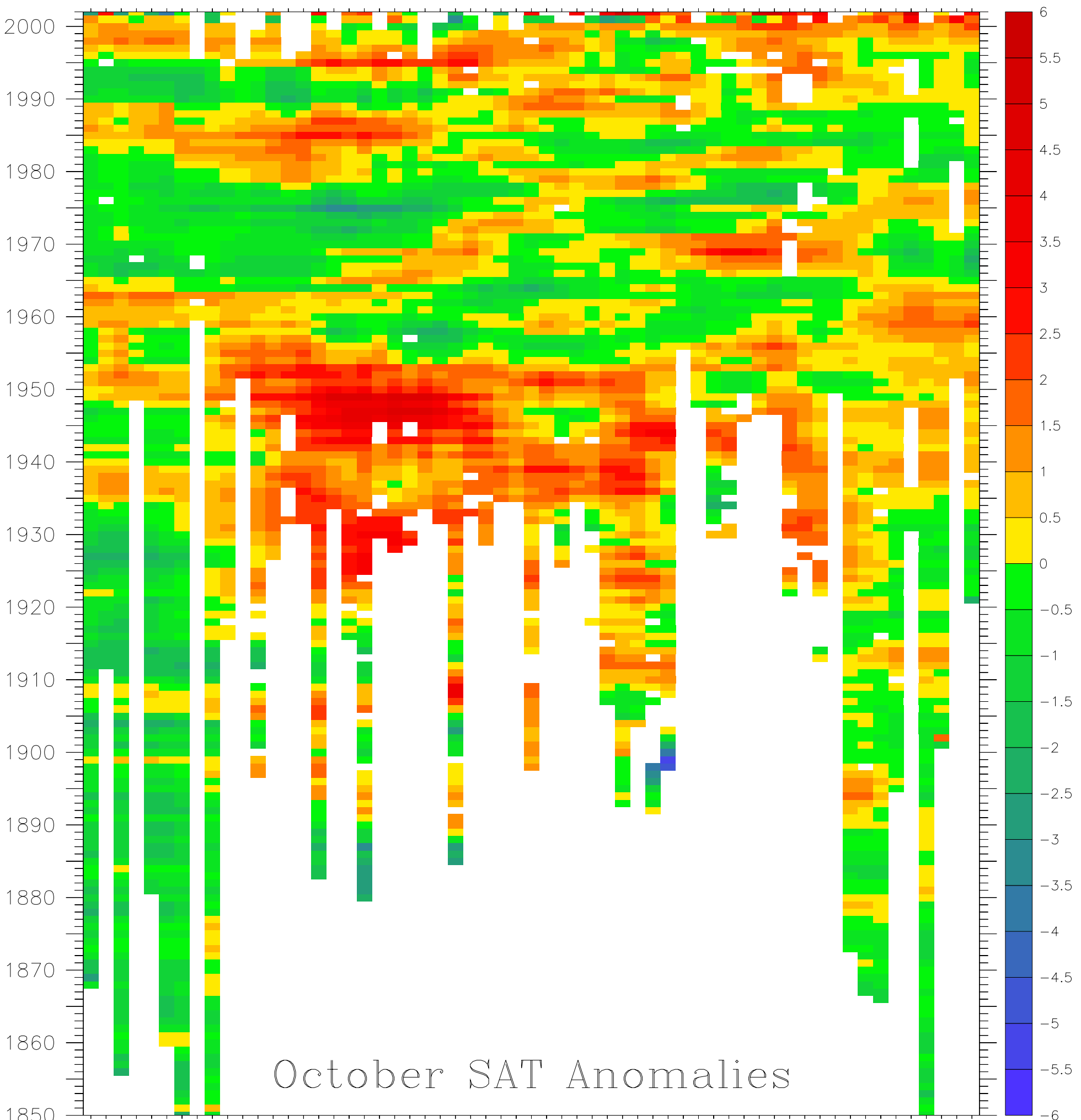

Figure 13 Time/longitude plots of temperature anomalies for fall (October) similar to Fig. 2. 


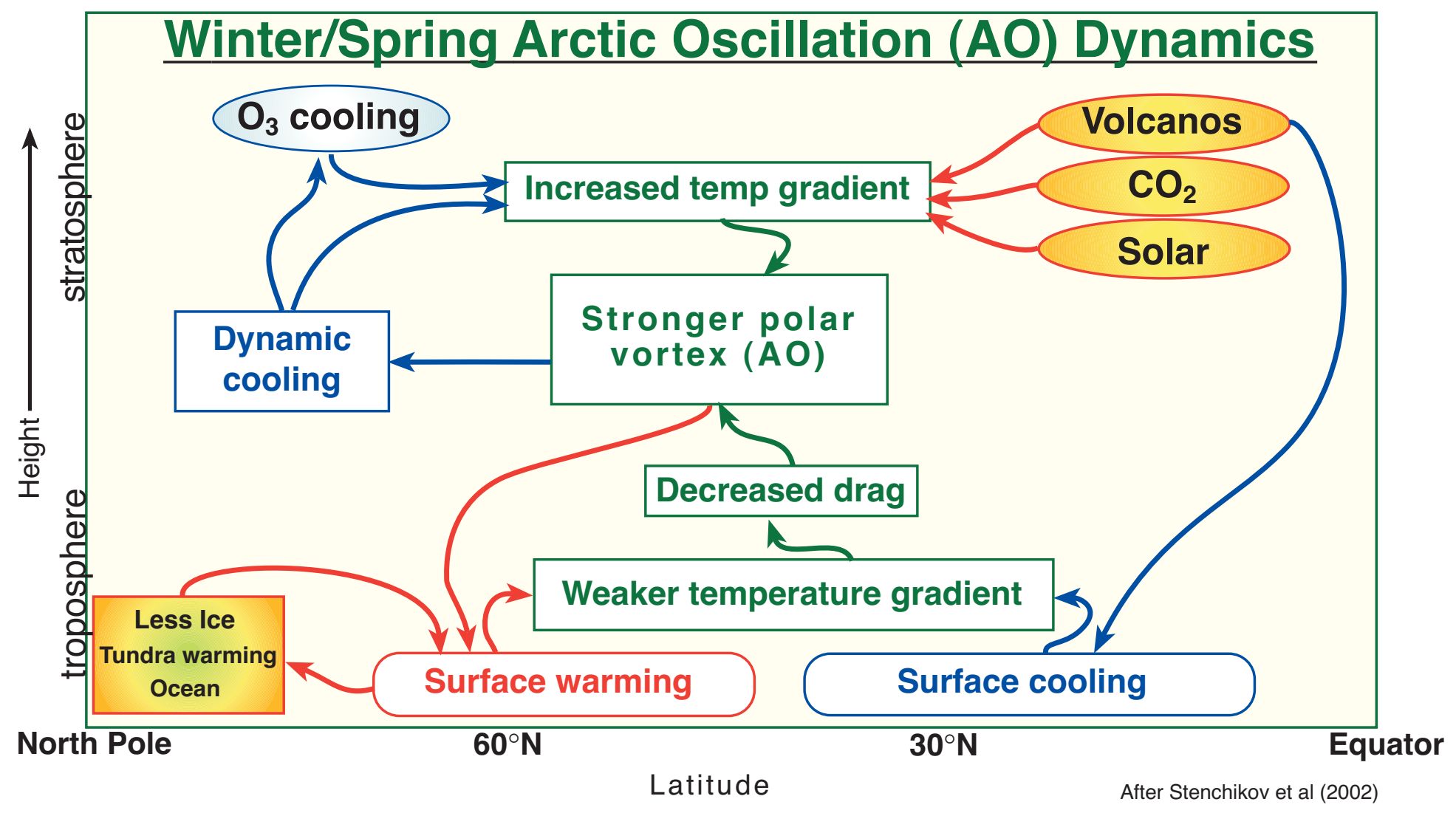

Figure 14 A hypothesized conceptual model of Arctic change. A chaotic polar vortex (AO) has a weak positive feedback through reduced low-level temperature gradients and the influence of dynamic cooling on ozone. The surface warming in the Arctic is stabilized by terrestrial, oceanic, and sea ice multi-year processes, while the system can be driven by latitudinal differences in radiative processes due to volcanic, carbon-dioxide, and solar forcing in the subtropics. 